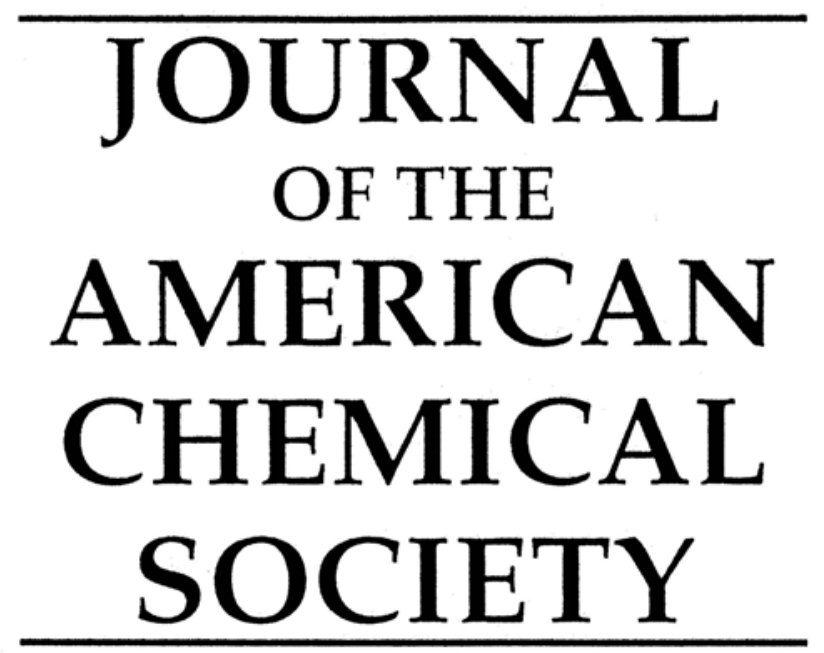

\title{
Design, Synthesis, and Conformational Dynamics of a Gated Molecular Basket
}

Veselin Maslak, Zhiqing Yan, Shijing Xia, Judith Gallucci,

Christopher M. Hadad, and Jovica D. Badjić*

The Ohio State University, Department of Chemistry, 100 W. 18th Avenue, Columbus, $\mathrm{OH} 43210$

\section{Supporting Information}

\begin{tabular}{|l|}
\hline \multicolumn{1}{|c|}{ Correspondence Address } \\
\hline Jovica Badjic \\
Assistant Professor \\
Department of Chemistry \\
The Ohio State University \\
100 W. 18 ${ }^{\text {th }}$ Avenue \\
Columbus, OH 43210 (USA) \\
Tel: (614) 247-8342 \\
Email: badjic@chemistry.ohio-state.edu
\end{tabular}


General: All chemicals were purchased from commercial sources, and used as received unless stated otherwise. All solvents were dried prior to use according to standard literature protocols. Chromatography purifications were performed using silica gel 60 (Sorbent technologies 40-75 $\mu \mathrm{m}, 200 \times 400 \mathrm{mesh}$ ). Thin-layer chromatography (TLC) was performed on silica-gel plate w/UV254 $(200 \mu \mathrm{m})$. Chromatograms were visualized by UV-light, and if need by staining using $20 \%$ phosphomolybdic acid in ethanol. Melting points were determined on an Electrothermal melting point apparatus in open capillaries and reported uncorrected. ${ }^{1} \mathrm{H}$ and ${ }^{13} \mathrm{C}$ NMR spectra were recorded, at $400 \mathrm{MHz}$ and $100 \mathrm{MHz}$, on a Bruker DRX-400 spectrometer. They were referenced using the solvent residual signal as internal standard. Samples were prepared using $\mathrm{CDCl}_{3}$ and $\mathrm{CD}_{3} \mathrm{SOCD}_{3}$ purchased from Cambridge Isotope Laboratories. The chemical shift values are expressed as $\delta$ values and the coupling constants values $(J)$ are in Hertz (Hz). The following abbreviations were used for signal multiplicities: $s$, singlet; $d$, doublet; $t$, triplet; $m$, multiplet; and br, broad. High resolution electron-ionization (HRMS-EI) spectra were recorded on a Micromass Q-TOF2 instrument.

Sample Preparation. All compounds, 1-4, used for preparation of $\mathrm{CDCl}_{3}$ solutions were dried in high vacuo at $80{ }^{\circ} \mathrm{C}$ using Kugelrorh distillation apparatus. The $\mathrm{CDCl}_{3}$ was freshly distilled from $\mathrm{CaH}_{2}$, and stored in a glove box. Syringes, NMR tubes, and IR cells were dried on a vacuum line at room temperature overnight, and stored in a desiccator. The $\mathrm{CDCl}_{3}$ stock solutions of all samples were prepared and handled in a glove box.

Vapor Pressure Osmometry Experiments. VPO measurements were made with a Knauer K7000 apparatus operated at $310 \mathrm{~K}$. HPLC-grade $\mathrm{CHCl}_{3}$ distilled from $\mathrm{CaH}_{2}$, was used in sample preparation. Calibration curves were obtained using sucrose octaacetate, triacetyl- $\beta$ cyclodextrine, and benzil as standards. 
Table S1. VPO data for benzil $\left(\mathrm{CHCl}_{3}, 310 \mathrm{~K}\right)$.

\begin{tabular}{|c|c|c|}
\hline Entry & $\begin{array}{c}\text { Concentration of } \\
\text { benzil }(\mathrm{mmol} / \mathrm{kg})\end{array}$ & $\begin{array}{c}\text { VPO reading } \\
(\mathrm{mV})\end{array}$ \\
\hline 1 & 0.9574 & $1.6 \pm 0.1$ \\
\hline 2 & 1.5958 & $2.4 \pm 0.1$ \\
\hline 3 & 2.6171 & $3.4 \pm 0.1$ \\
\hline 4 & 4.5400 & $5.7 \pm 0.1$ \\
\hline 5 & 5.6810 & $7.5 \pm 0.1$ \\
\hline 6 & 6.8866 & $8.3 \pm 0.1$ \\
\hline 7 & 8.3380 & $10.4 \pm 0.1$ \\
\hline 8 & 10.0534 & $12.2 \pm 0.1$ \\
\hline
\end{tabular}

${ }^{\text {a }}$ Reported values are mean values obtained from six measurements; the errors are presented as standard deviations.

Figure S1. VPO standard curve obtained for benzil in $\mathrm{CHCl}_{3}$ at $310 \mathrm{~K}$.

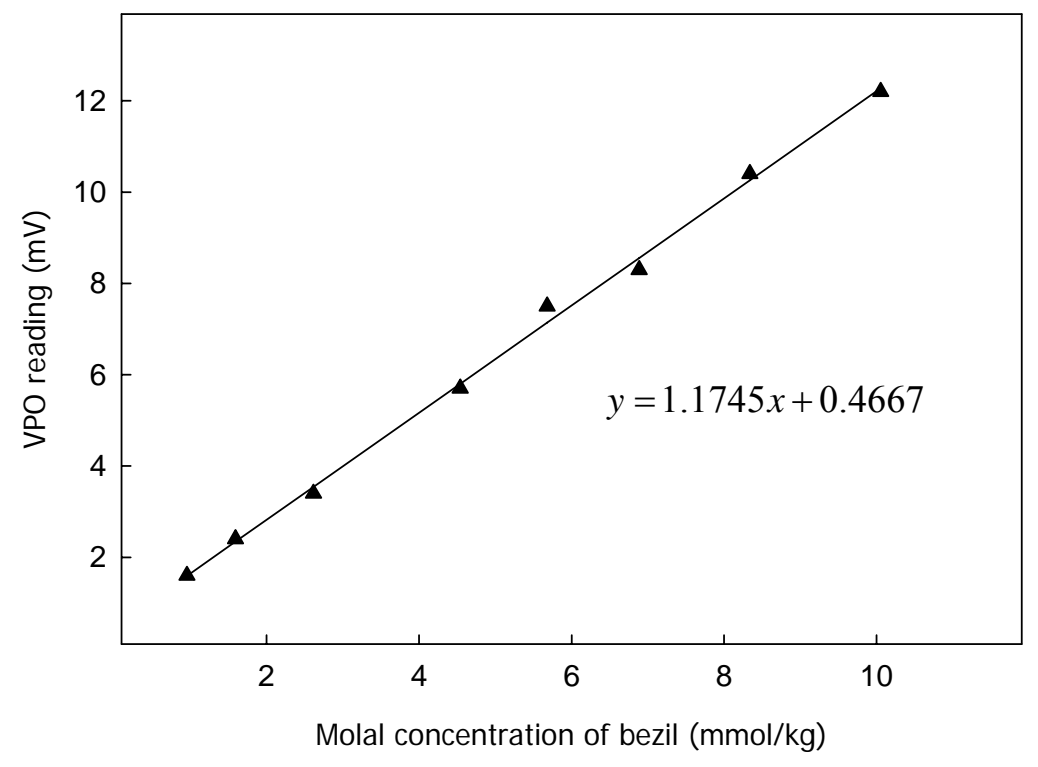


Figure S2. VPO standard curve obtained for benzil in $\mathrm{CHCl}_{3}$ at $310 \mathrm{~K}$.

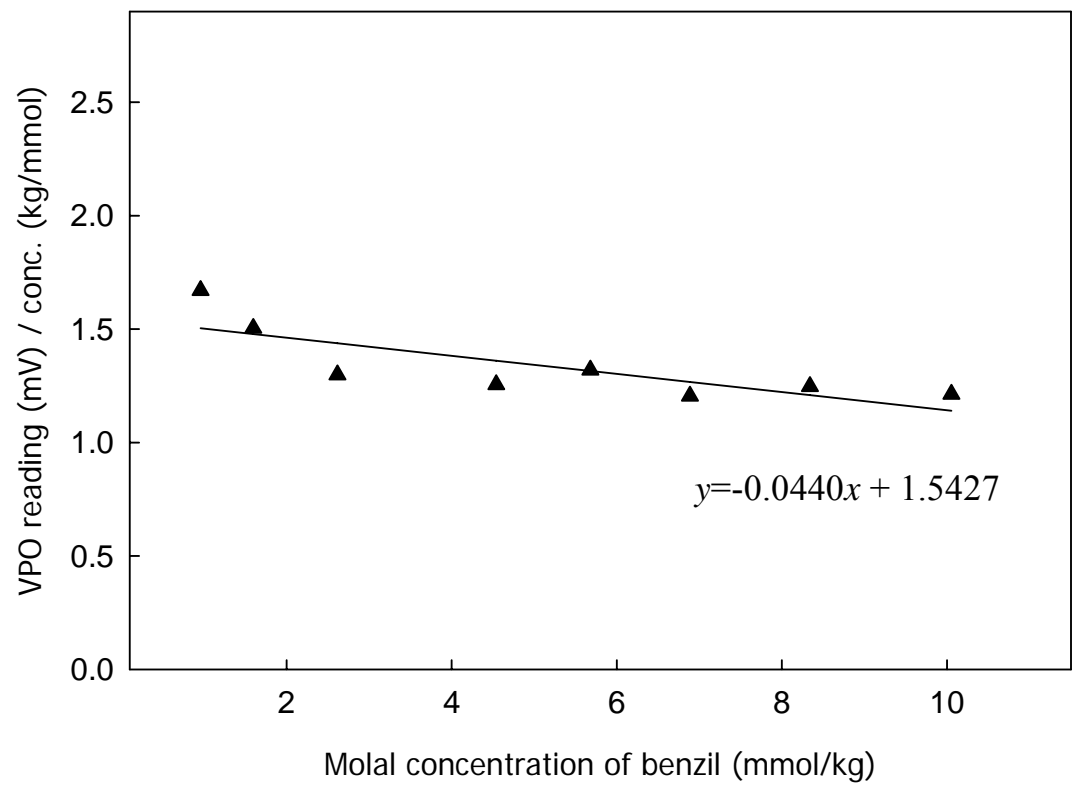

Table S2. VPO data for sucrose octaacetate $\left(\mathrm{CHCl}_{3}, 310 \mathrm{~K}\right)$ :

\begin{tabular}{|c|c|c|}
\hline Entry & $\begin{array}{c}\text { Concentration of } \\
\text { sucrose } \\
\text { octaacetate }(\mathrm{mmol} / \mathrm{kg})\end{array}$ & $\begin{array}{c}\text { VPO reading* } \\
(\mathrm{mV})\end{array}$ \\
\hline 1 & 1.3200 & $1.7 \pm 0.1$ \\
\hline 2 & 2.6200 & $3.6 \pm 0.1$ \\
\hline 3 & 5.2300 & $6.6 \pm 0.1$ \\
\hline 4 & 8.1900 & $10.4 \pm 0.1$ \\
\hline 5 & 11.3100 & $14.4 \pm 0.1$ \\
\hline 6 & 13.4500 & $18.3 \pm 0.1$ \\
\hline
\end{tabular}

*Reported values are mean values obtained from six measurements; the errors are shown as standard deviations. 
Figure S3. VPO standard curve obtained for sucrose octaacetate in $\mathrm{CHCl}_{3}$ at $310 \mathrm{~K}$.

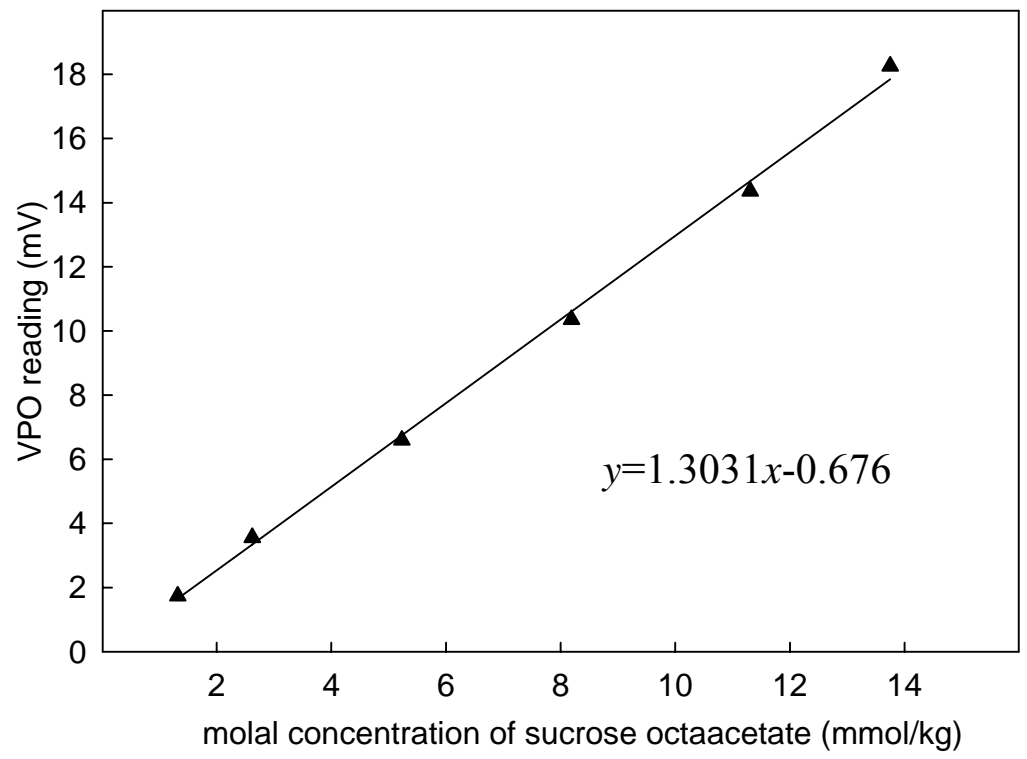

Figure S4. VPO standard curve obtained for sucrose octaacetate in $\mathrm{CHCl}_{3}$ at $310 \mathrm{~K}$.

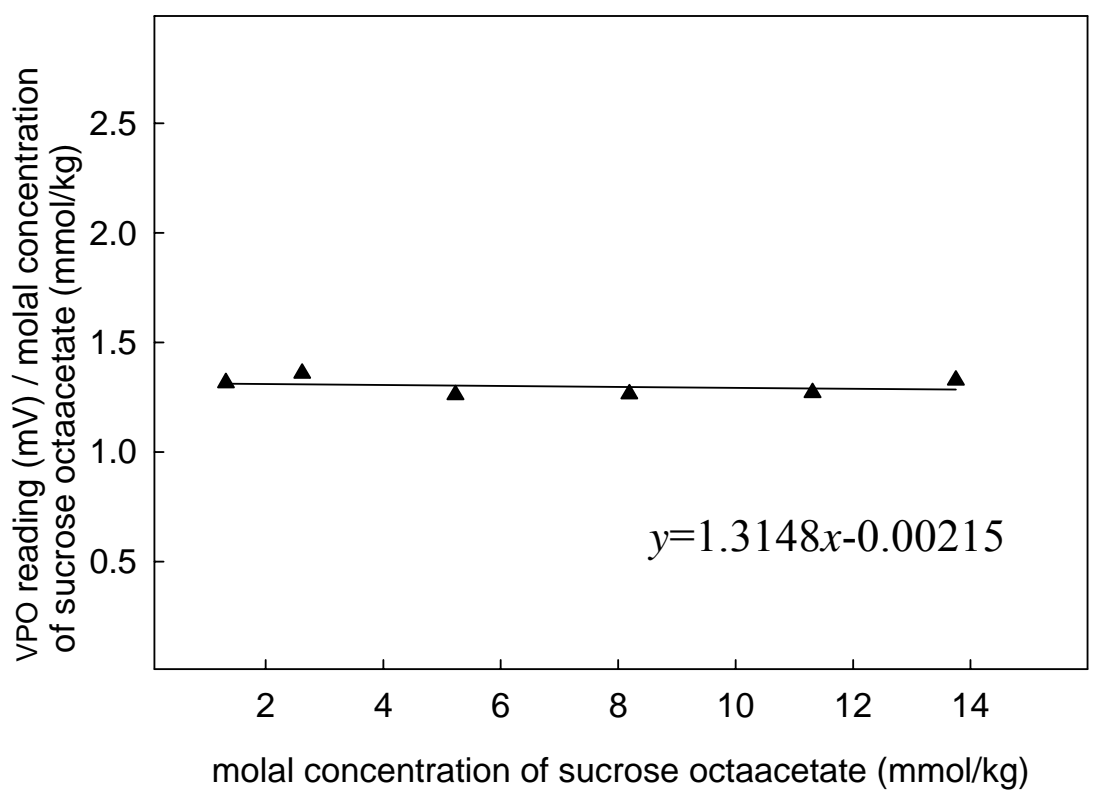


Table S3. VPO data for triacetyl- $\beta$-cyclodextrine $\left(\mathrm{CHCl}_{3}, 310 \mathrm{~K}\right)$.

\begin{tabular}{|c|c|c|}
\hline Entry & $\begin{array}{c}\text { Concentration of } \\
\text { triacetyl- } \beta- \\
\text { cyclodextrine } \\
(\mathrm{mmol} / \mathrm{kg})\end{array}$ & $\begin{array}{c}\text { VPO reading* } \\
(\mathrm{mV})\end{array}$ \\
\hline 1 & 0.6885 & $0.7 \pm 0.1$ \\
\hline 2 & 1.3238 & $1.5 \pm 0.1$ \\
\hline 3 & 3.1407 & $3.6 \pm 0.1$ \\
\hline 4 & 3.9573 & $4.6 \pm 0.1$ \\
\hline 5 & 4.9461 & $5.9 \pm 0.1$ \\
\hline 6 & 6.0462 & $7.5 \pm 0.1$ \\
\hline
\end{tabular}

*Reported values are mean values obtained from six measurements; the errors are shown as standard deviations.

Figure S5. VPO standard curve obtained for triacetyl- $\beta$-cyclodextrine in $\mathrm{CHCl}_{3}$ at $310 \mathrm{~K}$.

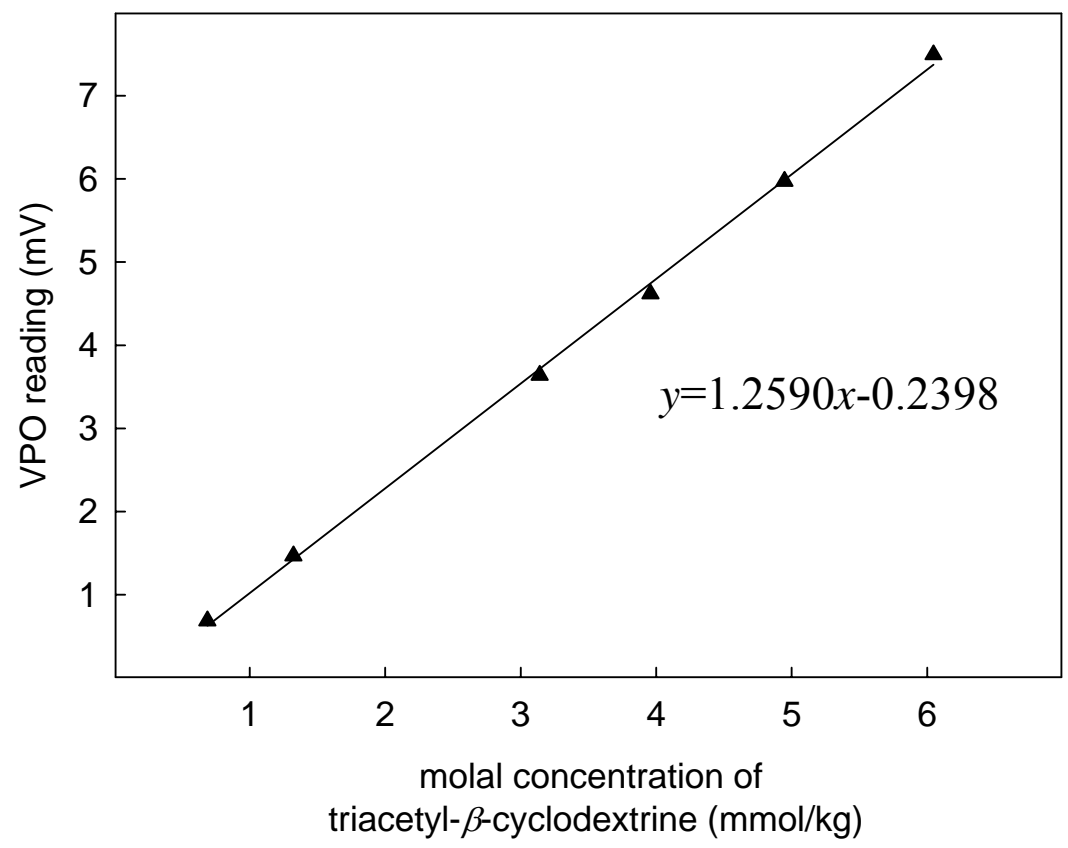


Figure S6. VPO standard curve obtained for triacetyl- $\beta$-cyclodextrine in $\mathrm{CHCl}_{3}$ at $310 \mathrm{~K}$.

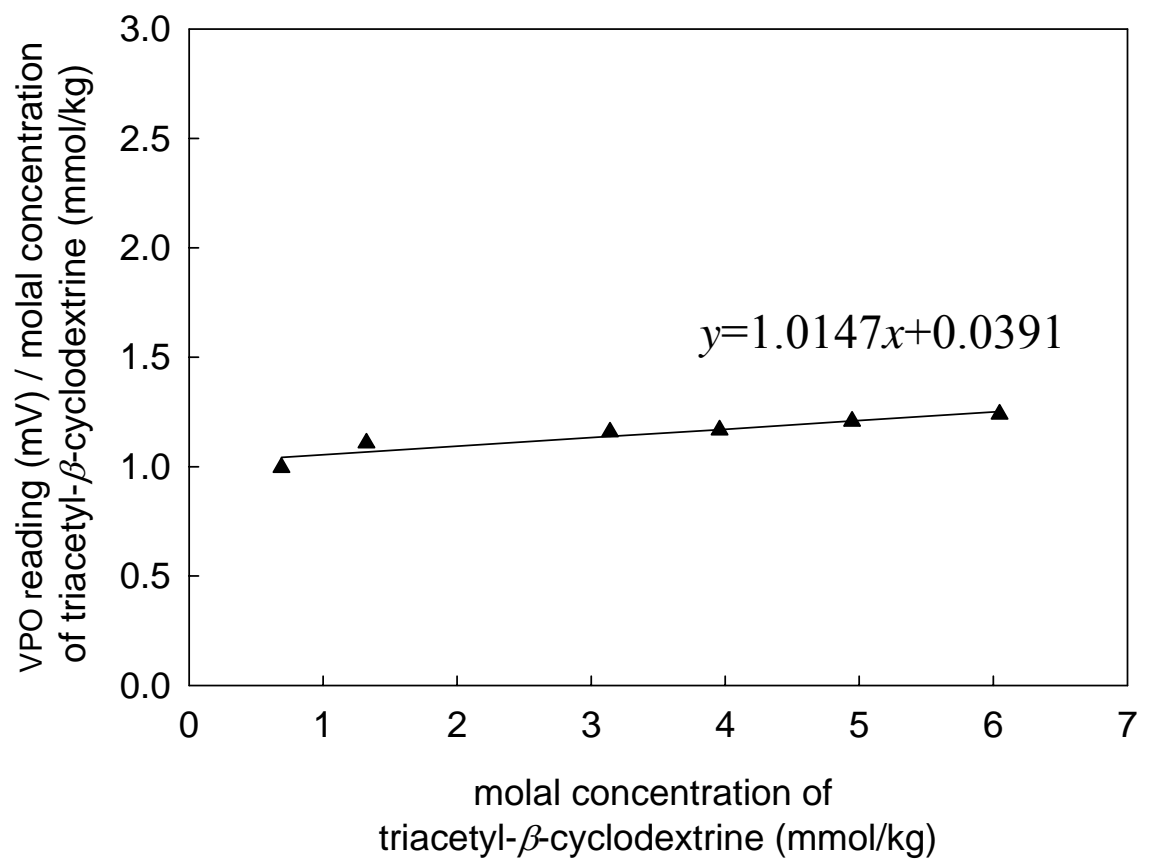

IR Experiments. FT-IR spectra were recorded on a Perkin-Elmer Spectrum GX spectrometer and are reported in terms of frequency of absorption $\left(\mathrm{cm}^{-1}\right)$. Spectra of 64 scans were obtained with $1 \mathrm{~cm}^{-1}$ resolution. Solvent subtraction was completed using a reference spectrum of a neat solvent. A long path, $10 \mathrm{~mm}$, liquid cell (New Era) with $\mathrm{KBr}$ windows was used in IR experiments. 
Figure S7. HR-DOSY spectra of: a) $0.50 \mathrm{mM}$, b) $0.33 \mathrm{mM}$, and c) $1.0 \mathrm{mM} \mathrm{CDCl} 3$ solution of 1 at $298 \mathrm{~K}(500 \mathrm{MHz})$.
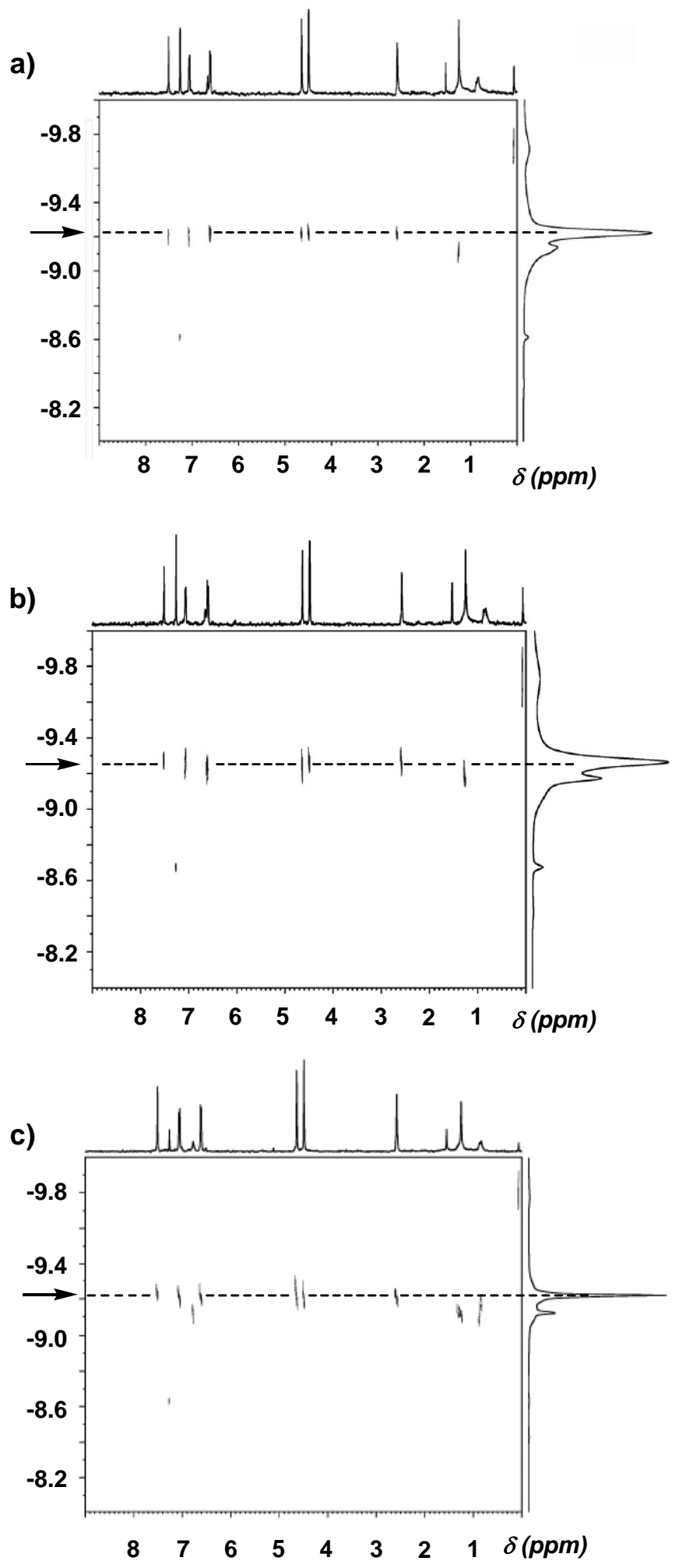
Figure S8. Variable temperature ${ }^{1} \mathrm{H}$ NMR spectra of $1.0 \mathrm{mM} \mathrm{CDCl} \mathrm{m}_{3}$ solution of 1 (400 $\mathrm{MHz})$.

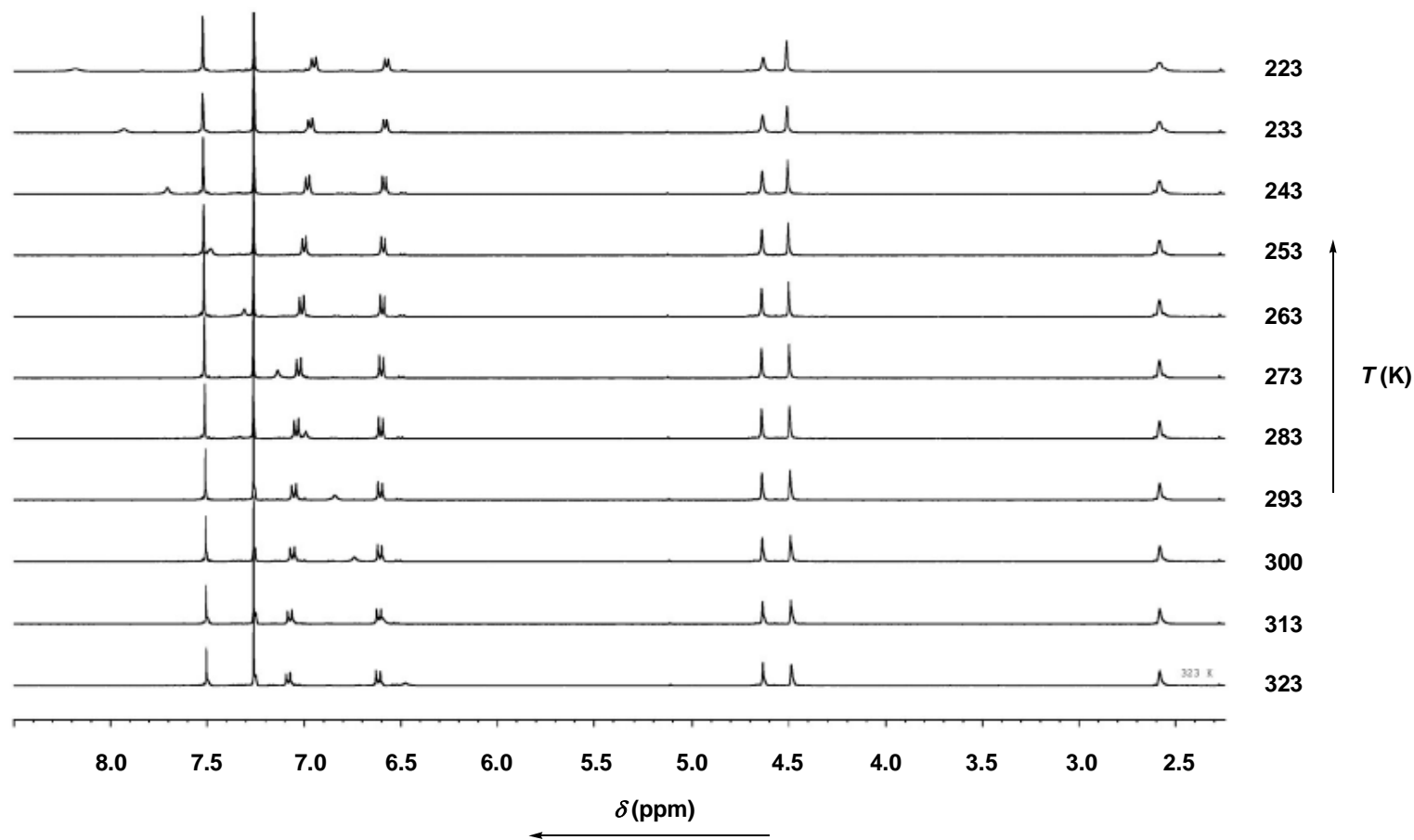

Figure 59. Variable temperature ${ }^{1} \mathrm{H}$ NMR spectra of $1.0 \mathrm{mM} \mathrm{CDCl} \mathrm{Cl}_{3}$ solution of 2 (400 $\mathrm{MHz})$.

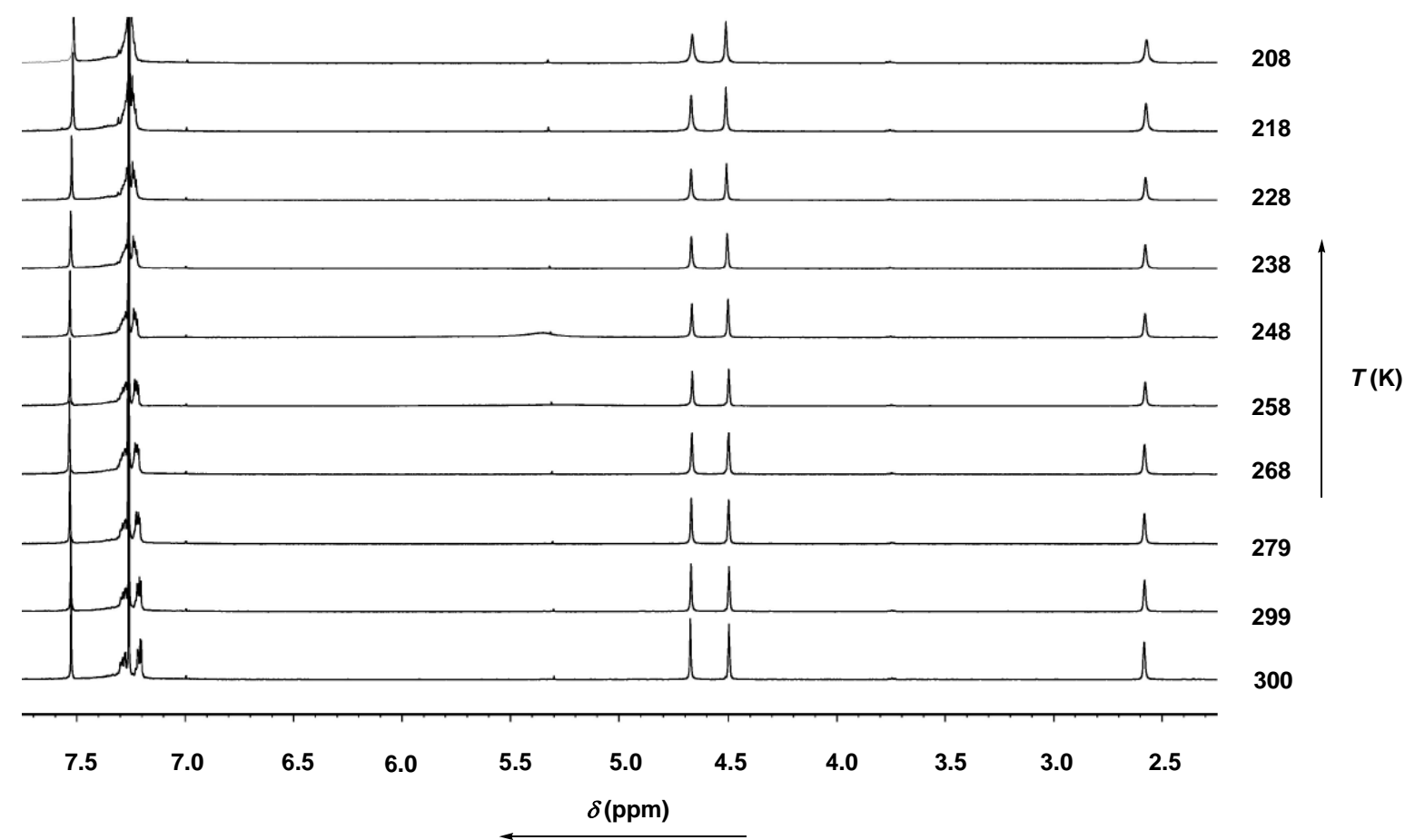


Figure S10. Variable temperature ${ }^{1} \mathrm{H}$ NMR spectra of $0.2 \mathrm{mM} \mathrm{CDCl}_{3}$ solution of 3 (400 $\mathrm{MHz}$ ).

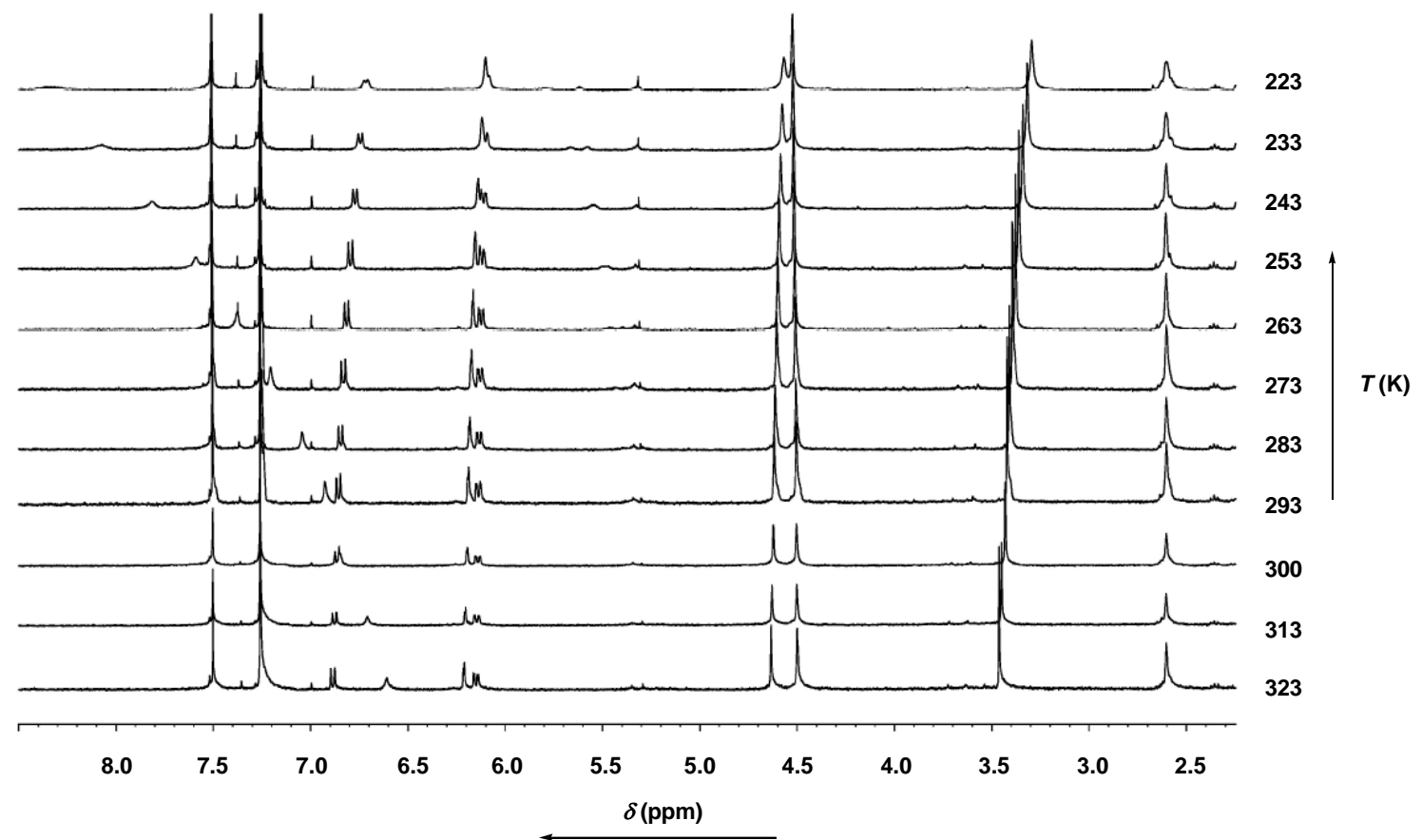

Figure S11. Variable temperature ${ }^{1} \mathrm{H}$ NMR spectra of $1.0 \mathrm{mM} \mathrm{CDCl}_{3}$ solution of 4 (400 $\mathrm{MHz}$.

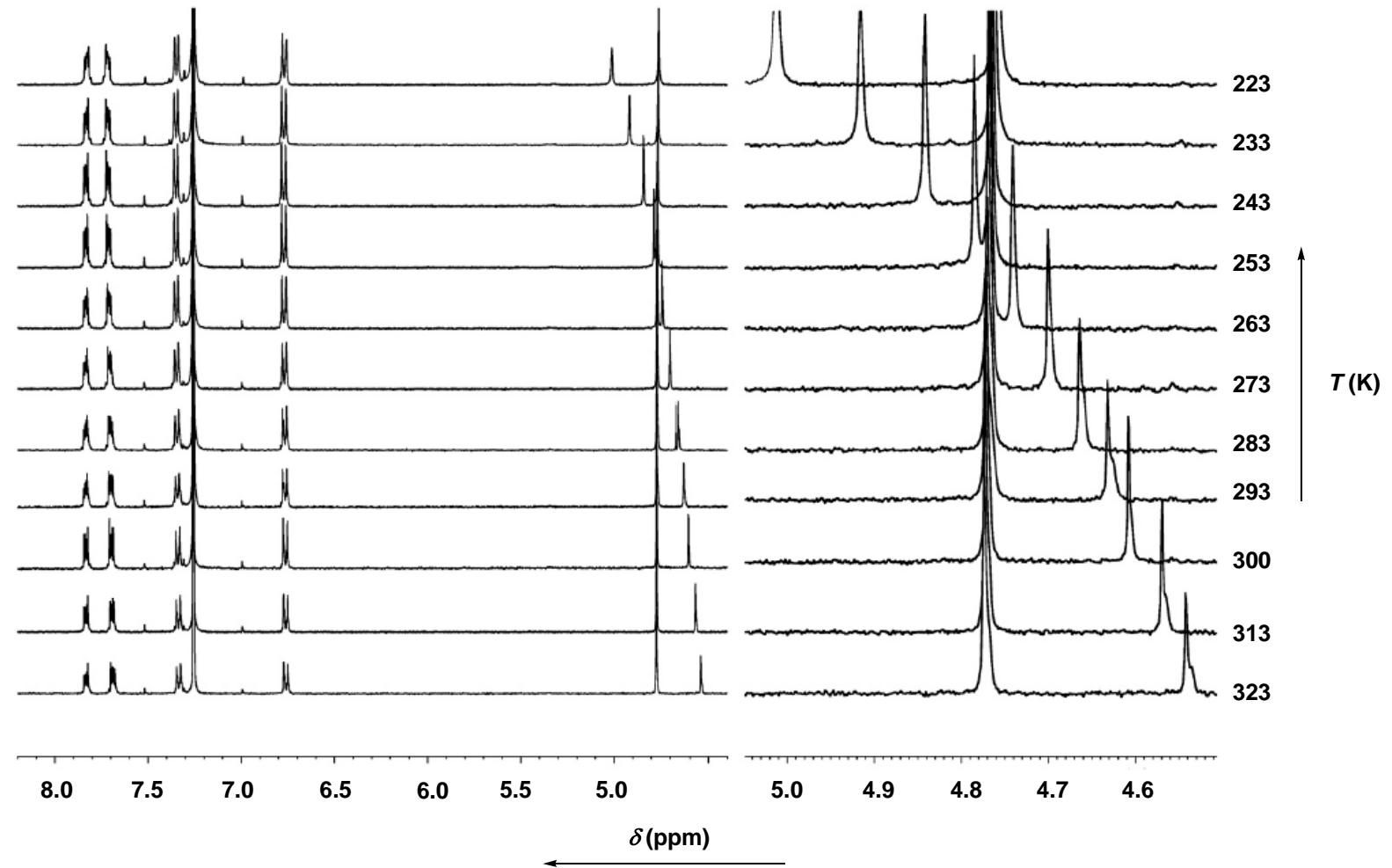


Figure S12. ${ }^{1} \mathrm{H}$ NMR chemical shifts $(\mathrm{Hz})$ for the $\mathrm{O}-\mathrm{H}$ proton in 4 against its mole fraction in $\mathrm{CDCl}_{3}$ at $298 \mathrm{~K}$. The non-linear curve fitting of the dilution ${ }^{1} \mathrm{H}$ NMR data to an EK isodesmic mathematical model (solid line) yielded an apparent association constant of $53 \pm 10 \mathrm{M}^{-1}$.

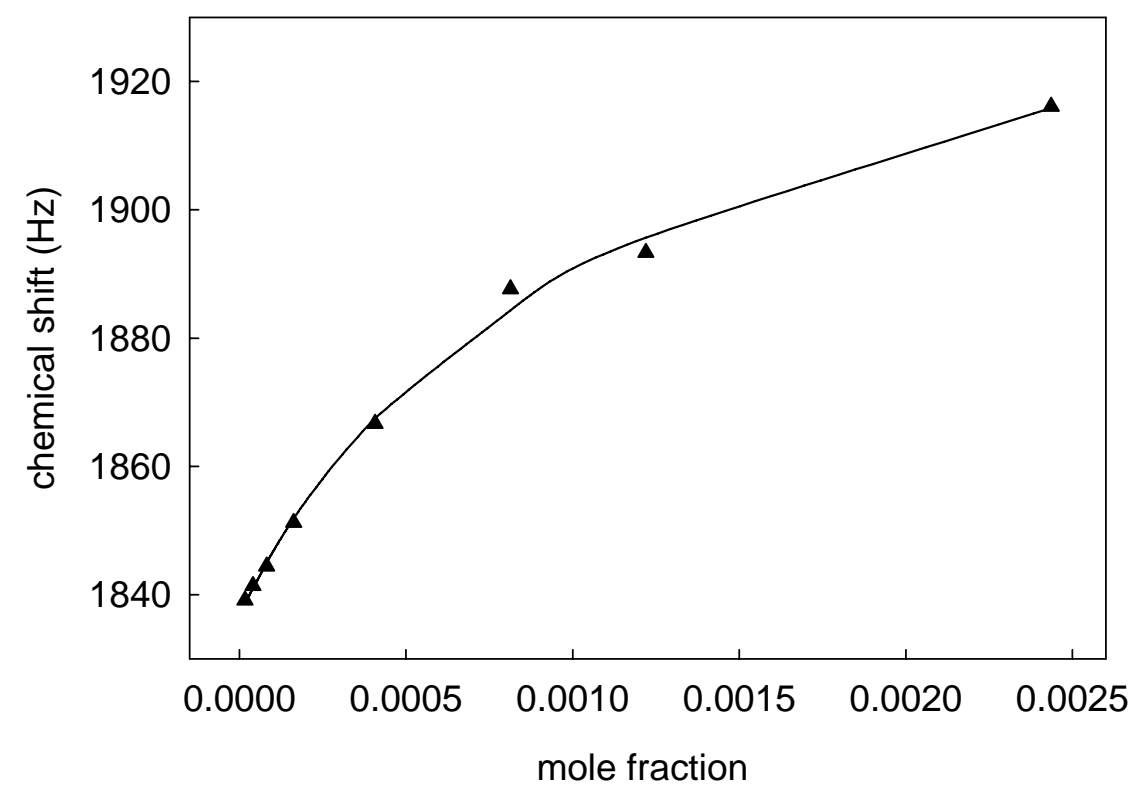

Figure S12. Normalized weight fractions for the oligomeric distribution of $5.0 \mathrm{mM} \mathrm{4,}$ obtained using the results of the nonlinear curve fitting of the ${ }^{1} \mathrm{H}$ NMR dilution data. ${ }^{1}$

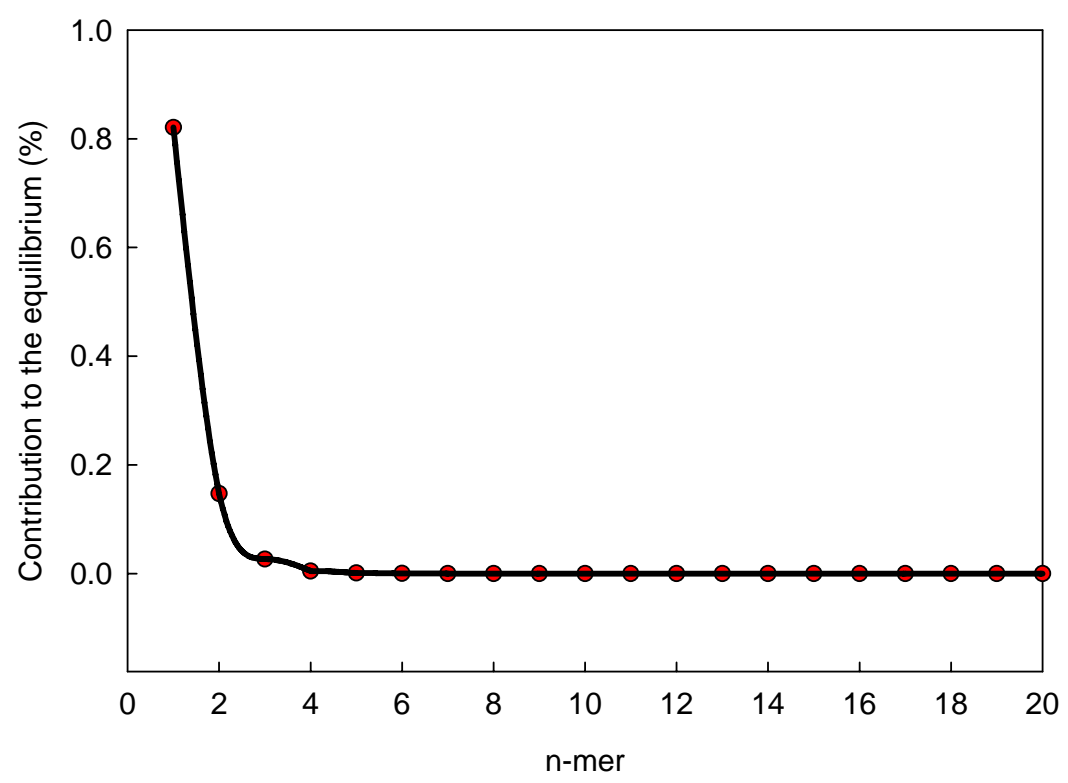

Molecular Modeling. Molecular modeling was carried out by molecular mechanics calculations. The calculations were performed by employing the MMFFs force field as implemented in the 
Maestro software (version 6.5.008) from Schrödinger, L.L.C. Monte Carlo conformational search (torsional sampling 10000 steps, energy window for saving structures $50 \mathrm{~kJ} / \mathrm{mol}$ ) using the $\mathrm{GB} / \mathrm{SA}$ continuum solvation model for $\mathrm{CHCl}_{3}$, generated conformers whose distribution population was analyzed by Boltzmann equation. The four distinct conformers (1 $\mathbf{a}$-d, Figure 1$)$ were further optimized using semiempirical PM3 method.

PM3 Theoretical Calculations. Semiempirical PM3 energy minimizations of the conformers $\mathbf{1}_{\mathbf{a}}-\mathbf{1}_{\mathbf{d}}$, generated by molecular mechanics, were performed using Gaussian 03 suite of programs. HF 6-31G* Theoretical Calculations. Hartee-Fock (HF) calculations were performed using Gaussian 03 suite of programs. For the compound 4, geometry optimization and vibrational frequency calculation were carried out at the HF level of theory, using the 6-31G* basis set in gaseous phase with the scaling factor of 0.9135 . For the compound $\mathbf{1}$, the geometries of the four conformers $\mathbf{1}_{\mathbf{a}-\mathbf{d}}$ were energy optimized at the HF/6-31G* level, while the vibrational frequency calculations were completed at the PM3 level, using the scaling factor of 0.9761.

Simulation of the IR Spectrum of 4. For the model compound 4, the experimental IR spectrum of its $4.8 \mathrm{mM} \mathrm{CHCl}_{3}$ solution was examined in the simulation procedure. Two $\mathrm{O}-\mathrm{H}$ stretching vibrations, one at $3755 \mathrm{~cm}^{-1}$ and one at $3700 \mathrm{~cm}^{-1}$, comprise the $\mathrm{O}-\mathrm{H}$ stretching part of the calculated infrared spectrum of a dimer of 4 (HF/6-31G*). These vibrations correspond to the free and hydrogen-bonded $\mathrm{O}-\mathrm{H}$ groups, respectively. Only one $\mathrm{O}-\mathrm{H}$ stretching vibrations, at $3761 \mathrm{~cm}^{-1}$, however, is revealed in the calculated infrared spectrum of the monomeric 4 (HF/6$31 \mathrm{G}^{*}$ ). The experimental spectra were simulated by a curve-fitting routine (IGOR) using two Gaussian functions. In this simulation, the broadening (FWHM) of each peak was kept the same for all calculated peaks to determine the contribution of the monomeric and dimeric $\mathbf{4}$ to the experimental spectrum. The simulated IR spectrum of 4,(see Figure $6 \mathrm{c}$ in the text), was best simulated with the 89:11 percentage contributions of its monomeric and dimeric forms, respectively. Interestingly, this ratio corresponds well to the experimentally found ratio (82:15 for $5.0 \mathrm{mM}$ ) of 4 in $\mathrm{CHCl}_{3}$.

Simulation of the IR Spectrum of 1. For the compound 1, the experimental IR spectrum of its $4.4 \mathrm{mM} \mathrm{CHCl}_{3}$ solution was examined in the simulation procedure. The three experimentally found $\mathrm{O}-\mathrm{H}$ stretching vibrations, an intense (at $3581 \mathrm{~cm}^{-1}$ ), a broad (at $3402 \mathrm{~cm}^{-1}$ ) and a shoulder (at $3460 \mathrm{~cm}^{-1}$ ) were curve-fitted by four Gaussian functions using the IGOR software. Importantly, an attempt to simulate the experimental spectrum with three Gaussian functions 
resulted in a poor fit. Evidently, there are at least four vibrational frequencies (from different conformers) which contribute to the observed $\mathrm{O}-\mathrm{H}$ stretching. Based on the HF/6-31G* computational results, the conformer $\mathbf{1}_{\mathbf{a}}$ dominates the equilibrium (94\% of the Boltzmann distribution). The conformer $\mathbf{1}_{\mathbf{b}}$ is less stable and contributes only $3.5 \%$ to the equilibrium. The partially open $\mathbf{1}_{\mathbf{d}}$ and fully open $\mathbf{1}_{\mathrm{c}}$ conformers are energetically disfavored and collectively contribute just $2.5 \%$. Using the calculated widths of the peaks from the curve-fitting of the experimental spectrum, vibrational frequencies from the PM3 calculations, and Boltzmann contributions from HF/6-31G* single-point energies, the composite IR spectrum of a fractionweighted mixture of the conformers of $\mathbf{1}$ was computed.

\section{Preparation of the Starting Materials}

Compound 5: A mixture of freshly distilled cyclopentadiene (2.65 g, $0.04 \mathrm{~mol})$ and cis-1,4dichloro-2-butene $(4.16 \mathrm{~g}, 0.033 \mathrm{~mol})$ in benzene $(3 \mathrm{~mL})$ was heated at $180^{\circ} \mathrm{C}$ for $5 \mathrm{~h}$ in a sealed tube. The reaction mixture was then cooled to room temperature, and benzene was evaporated under reduced pressure. The remaining residue was distilled in vacuo to afford $\mathbf{5}$ as a colorless oil (4.5 g, $71 \%$ \%). B.p. $=85.0{ }^{\circ} \mathrm{C}$ at $0.5 \mathrm{mmHg} ;{ }^{1} \mathrm{H}$ NMR $\left(400 \mathrm{MHz}, \mathrm{CDCl}_{3}, 25^{\circ} \mathrm{C}\right): \delta=6.25(\mathrm{dd}$, $\left.2 \mathrm{H}, J_{1}=J_{2}=1.8 \mathrm{~Hz}\right), 3.31\left(\mathrm{dd}, 2 \mathrm{H}, J_{1}=5.7 \mathrm{~Hz}, J_{2}=10.7 \mathrm{~Hz}\right), 3.14-3.09(\mathrm{~m}, 4 \mathrm{H}), 2.63-2.60(\mathrm{~m}$, $2 \mathrm{H}), 1.55(\mathrm{~m}, 1 \mathrm{H})$, and $1.37 \mathrm{ppm}(\mathrm{d}, 1 \mathrm{H}, J=8.6 \mathrm{~Hz}) ;{ }^{13} \mathrm{C} \mathrm{NMR}\left(100 \mathrm{MHz}, \mathrm{CDCl}_{3}, 25{ }^{\circ} \mathrm{C}\right): \delta=$ 135.6 $(\mathrm{CH}), 48.4\left(\mathrm{CH}_{2}\right), 46.6(\mathrm{CH}), 45.6(\mathrm{CH})$, and $45.0 \mathrm{ppm}\left(\mathrm{CH}_{2}\right)$. MS(ESI): $\mathrm{m} / \mathrm{z}$ calcd for $\mathrm{C}_{9} \mathrm{H}_{12} \mathrm{Cl}_{2} \mathrm{Na}$ : $213.0[\mathrm{M}+\mathrm{Na}]^{+}$; found: 213.0.

Compound 6: To a cis-decaline $(30 \mathrm{~mL})$ solution of $5(1.67 \mathrm{~g}, 8.7 \mathrm{mmol})$ at $150{ }^{\circ} \mathrm{C}$, neat bromine ( $1.54 \mathrm{~g}, 8.7 \mathrm{mmol})$ was added slowly over five minutes. The mixture was stirred at the same temperature for 15 minutes, upon which the solvent was removed in vacuo. The residue was purified by column chromatography $\left(\mathrm{SiO}_{2}\right.$, hexanes $\left./ \mathrm{CH}_{2} \mathrm{Cl}_{2}, 8: 2\right)$ to afford 6 as a white solid $(1.84 \mathrm{~g}, 61 \%)$. M. p. $96{ }^{\circ} \mathrm{C} ;{ }^{1} \mathrm{H}$ NMR $\left(400 \mathrm{MHz}, \mathrm{CDCl}_{3}, 25{ }^{\circ} \mathrm{C}\right): \delta=4.46(\mathrm{~d}, 2 \mathrm{H}, J=2.0 \mathrm{~Hz})$, $3.66\left(\mathrm{dd}, 2 \mathrm{H}, J_{1}=6.6 \mathrm{~Hz}, J_{2}=11.4 \mathrm{~Hz}\right), 3.41\left(\mathrm{dd}, 2 \mathrm{H}, J_{1}=9.8 \mathrm{~Hz}, J_{2}=11.3 \mathrm{~Hz}\right), 2.89(\mathrm{t}, 2 \mathrm{H}, J=$ $1.8 \mathrm{~Hz}), 2.54-2.51(\mathrm{~m}, 2 \mathrm{H}), 2.40(\mathrm{~d}, 1 \mathrm{H}, J=11.0 \mathrm{~Hz})$, and $1.56 \mathrm{ppm}\left(\mathrm{dt}, 1 \mathrm{H}, J_{1}=1.6 \mathrm{~Hz}, J_{2}=\right.$ $11.0 \mathrm{~Hz}) ;{ }^{13} \mathrm{C} \mathrm{NMR}\left(100 \mathrm{MHz}, \mathrm{CDCl}_{3}, 25^{\circ} \mathrm{C}\right): \delta=52.7(\mathrm{CH}), 50.9(\mathrm{CH}), 43.5(\mathrm{CH}), 40.9\left(\mathrm{CH}_{2}\right)$, and $34.4 \mathrm{ppm}\left(\mathrm{CH}_{2}\right)$; HRMS(ESI): $\mathrm{m} / \mathrm{z}$ calcd for $\mathrm{C}_{9} \mathrm{H}_{12} \mathrm{Br}_{2} \mathrm{Cl}_{2} \mathrm{Na}: 372.8558[\mathrm{M}+\mathrm{Na}]^{+}$; found: 372.8571 . 


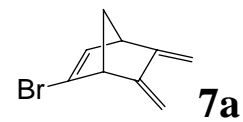

Compound 7a: To a solution of $6(2.4 \mathrm{~g}, 6.8 \mathrm{mmol})$ in $\mathrm{THF}(68 \mathrm{~mL})$ at $0{ }^{\circ} \mathrm{C}$, potassium tertbutoxide (14.5 g, $0.14 \mathrm{~mol}$ ) was added under an argon atmosphere. The reaction mixture was left to stir for $2 \mathrm{~h}$, before being washed with water $(6 \mathrm{~mL})$, and extracted with hexane $(3 \mathrm{x} 50 \mathrm{~mL})$. The organic phase was dried $\left(\mathrm{MgSO}_{4}\right)$, and evaporated under reduced pressure. The solid residue was purified by column chromatography $\left(\mathrm{SiO}_{2}\right.$, hexanes) to afford 7a as a colorless oil (1.1 g, 82 \%). ${ }^{1} \mathrm{H}$ NMR (400 MHz, $\left.\mathrm{CDCl}_{3}, 25^{\circ} \mathrm{C}\right): \delta=6.20(\mathrm{~d}, 1 \mathrm{H}, J=3.1 \mathrm{~Hz}), 5.31(\mathrm{~s}, 1 \mathrm{H}), 5.25(\mathrm{~s}, 1 \mathrm{H})$, $5.13(\mathrm{~s}, 1 \mathrm{H}), 5.00(\mathrm{~s}, 1 \mathrm{H}), 3.36(\mathrm{~s}, 1 \mathrm{H})$, and $3.30 \mathrm{ppm}(\mathrm{s}, 1 \mathrm{H}) ;{ }^{13} \mathrm{C} \mathrm{NMR}\left(100 \mathrm{MHz}, \mathrm{CDCl}_{3}, 25\right.$ $\left.{ }^{\circ} \mathrm{C}\right): \delta=135.4(\mathrm{CH}), 103.4\left(\mathrm{CH}_{2}\right), 102.4\left(\mathrm{CH}_{2}\right), 58.7(\mathrm{CH}), 52.2(\mathrm{CH})$ and $50.9 \mathrm{ppm}\left(\mathrm{CH}_{2}\right)$; HRMS(ESI): $m / z$ calcd for $\mathrm{C}_{9} \mathrm{H}_{10} \mathrm{Br}: 196.9960[M+\mathrm{H}]^{+}$; found: 197.0033 .

Compound 7: To a solution of dry diisopropylamine (2.06 g, $20.4 \mathrm{mmol})$ in THF (20 ml) at 0 ${ }^{\circ} \mathrm{C}$, $n$-butyl lithium (1.6 M in hexanes, $\left.12.8 \mathrm{~mL}, 20.4 \mathrm{mmol}\right)$ was added under an atmosphere of argon. The reaction mixture was cooled to $-78^{\circ} \mathrm{C}$, and a solution of $6 \mathrm{a}(1.0 \mathrm{~g}, 5.1 \mathrm{mmol})$ in THF $(5 \mathrm{ml})$ was added dropwise over 10 minutes. The resulting mixture was stirred for additional 30 minutes before a solution of trimethyltin chloride $(1.2 \mathrm{~g}, 6.1 \mathrm{mmol})$ in THF $(5 \mathrm{ml})$ was added. Upon 30 minutes at $-78^{\circ} \mathrm{C}$, the reaction mixture was gradually warmed to room temperature and left to stir overnight. The resulting mixture was washed with water $(30 \mathrm{~mL})$ and extracted with diethyl ether $(3 \times 50 \mathrm{~mL})$. The combined organic phase was dried $\left(\mathrm{MgSO}_{4}\right)$ and concentrated in vacuo. The solid residue was purified by column chromatography $\left(\mathrm{SiO}_{2}\right.$, hexanes $\left./ \mathrm{CH}_{2} \mathrm{Cl}_{2}, 9: 1\right)$ to afford 7 as a colorless oil $(1.56 \mathrm{~g}, 85 \%) .{ }^{1} \mathrm{H}$ NMR $\left(400 \mathrm{MHz}, \mathrm{CDCl}_{3}, 25{ }^{\circ} \mathrm{C}\right): \delta=5.26(\mathrm{~s}, 1 \mathrm{H})$, $5.18(\mathrm{~s}, 1 \mathrm{H}), 5.09(\mathrm{~s}, 1 \mathrm{H}), 4.90(\mathrm{~s}, 1 \mathrm{H}), 3.42(\mathrm{~s}, 1 \mathrm{H}), 3.30(\mathrm{~s}, 1 \mathrm{H}), 1.99\left(\mathrm{dt}, 1 \mathrm{H}, J_{1}=1.4 \mathrm{~Hz}, J_{2}=8.4\right.$ $\mathrm{Hz}), 1.61\left(\mathrm{dt}, J_{1}=1.5 \mathrm{~Hz}, J_{2}=8.4 \mathrm{~Hz}\right)$ and $0.23 \mathrm{ppm}(\mathrm{t}, 9 \mathrm{H}, J=28.4 \mathrm{~Hz}) ;{ }^{13} \mathrm{C} \mathrm{NMR}(100 \mathrm{MHz}$, $\left.\mathrm{CDCl}_{3}, 25^{\circ} \mathrm{C}\right): \delta=148.9,147.3,147.1,138.5,103.0,101.1,60.5,57.5,50.7$ and $-8.9 \mathrm{ppm}$. MS(ESI): $\mathrm{m} / \mathrm{z}$ calcd for $\mathrm{C}_{12} \mathrm{H}_{17} \mathrm{BrSn}: 359.95[M]^{+}$; found: 359.3 .

Compound 8: To a solution of $7(1.0 \mathrm{~g}, 2.8 \mathrm{mmol})$ in 1-Methyl-2-pyrrolidinone $(20 \mathrm{~mL})$, cooled to $-20{ }^{\circ} \mathrm{C}$ and under an atmosphere of argon, copper(I)thiophenecarboxylate $(0.79 \mathrm{~g}, 4.2 \mathrm{mmol})$ was added portionwise. The reaction mixture was gradually warmed to room temperature and stirred for an additional $12 \mathrm{~h}$. An aqueous solution of aqueous $\mathrm{NH}_{3}(10 \%, 10 \mathrm{ml})$ was added to this mixture which was subsequently extracted with diethyl ether $(2 \times 100 \mathrm{~mL})$. The combined organic phase was dried $\left(\mathrm{MgSO}_{4}\right)$ and concentrated under reduced pressure. The resulting solid 
residue was purified by column chromatography $\left(\mathrm{SiO}_{2}\right.$, hexanes $\left./ \mathrm{CH}_{2} \mathrm{Cl}_{2}, 8: 2\right)$ to afford syn-8 as a white solid (42 mg, $13 \%$ ). M. p. $\left.240{ }^{\circ} \mathrm{C} ;{ }^{1} \mathrm{H} \mathrm{NMR} \mathrm{(400} \mathrm{MHz,} \mathrm{CDCl}_{3}, 25{ }^{\circ} \mathrm{C}\right): \delta=5.06(\mathrm{~s}, 6 \mathrm{H})$, $4.93(\mathrm{~s}, 6 \mathrm{H}), 3.85(\mathrm{t}, 6 \mathrm{H}, J=1.5 \mathrm{~Hz}), 2.06\left(\mathrm{dt}, 3 \mathrm{H}, J_{1}=1.5 \mathrm{~Hz}, J_{2}=8.6 \mathrm{~Hz}\right)$ and1.61 ppm (dt, , $\left.J_{1}=1.6 \mathrm{~Hz}, J_{2}=8.6 \mathrm{~Hz}\right) ;{ }^{13} \mathrm{C} \mathrm{NMR}\left(100 \mathrm{MHz}, \mathrm{CDCl}_{3}, 25{ }^{\circ} \mathrm{C}\right): \delta=148.1(\mathrm{C}), 135.6(\mathrm{CH}), 101.8$ $\left(\mathrm{CH}_{2}\right), 51.3\left(\mathrm{CH}_{2}\right)$, and $50.3 \mathrm{ppm}(\mathrm{CH}) ; \mathrm{HRMS}(\mathrm{ESI}): \mathrm{m} / \mathrm{z}$ calcd for $\mathrm{C}_{27} \mathrm{H}_{24} \mathrm{Na}: 371.1776$ $[M+\mathrm{Na}]^{+}$; found: 371.1781 .

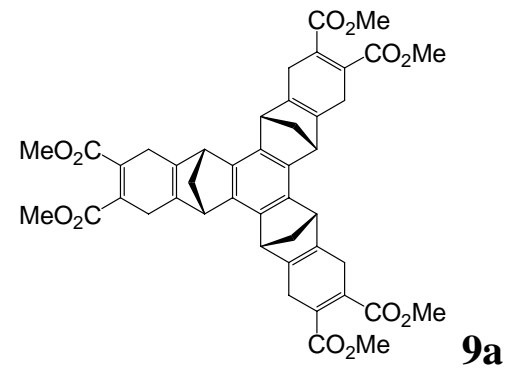

Compound 9a: A solution of syn-8 $(55 \mathrm{mg}, 0.158 \mathrm{mmol})$ and dimethylacetylene dicarboxylate (112 $\mathrm{mg}, 0.79 \mathrm{mmol})$ in toluene $(3.0 \mathrm{~mL})$ was subjected to a high pressure $(14,000 \mathrm{psi})$ for $4 \mathrm{~d}$. The reaction was judged to be completed by $\mathrm{TLC}\left(\mathrm{SiO}_{2}\right.$, benzene/acetone, 8:2). Toluene was evaporated in vacuo and the crude product purified by column chromatography to yield 9a as white solid (109 mg, $89 \%$ ). M. p. $\left.215^{\circ} \mathrm{C} ;{ }^{1} \mathrm{H} \mathrm{NMR} \mathrm{(400} \mathrm{MHz,} \mathrm{CDCl}_{3}, 25{ }^{\circ} \mathrm{C}\right): \delta=3.62$ (s, $\left.18 \mathrm{H}\right)$, $3.55(\mathrm{~s}, 6 \mathrm{H}), 3.21-3.15(\mathrm{~m}, 6 \mathrm{H}), 2.75-2.67(\mathrm{~m}, 6 \mathrm{H}), 2.14(\mathrm{~d}, 2 \mathrm{H}, J=7.2 \mathrm{~Hz})$, and $1.97 \mathrm{ppm}(\mathrm{d}$, $2 \mathrm{H}, J=7.2 \mathrm{~Hz}) ;{ }^{13} \mathrm{C} \mathrm{NMR}\left(100 \mathrm{MHz}, \mathrm{CDCl}_{3}, 25{ }^{\circ} \mathrm{C}\right): \delta=168.4(\mathrm{C}), 141.9(\mathrm{C}), 147.1(\mathrm{C}), 133.1$ C, $63.3\left(\mathrm{CH}_{2}\right), 51.9(\mathrm{CH}), 49.3\left(\mathrm{CH}_{3}\right)$, and $28.3 \mathrm{ppm}\left(\mathrm{CH}_{2}\right) ; \mathrm{HRMS}(\mathrm{EI}): \mathrm{m} / \mathrm{z}$ calcd for $\mathrm{C}_{45} \mathrm{H}_{42} \mathrm{O}_{12} \mathrm{Na}$ : 797.2569 [M+Na] $]^{+}$; found: 797.2564.

Compound 9: The compound 9a (120 mg, $0.16 \mathrm{mmol})$ was dissolved in $\mathrm{CH}_{2} \mathrm{Cl}_{2}(15 \mathrm{~mL})$ and then DDQ ( $88 \mathrm{mg}, 0.62 \mathrm{mmol}$ ) was added at room temperature. The resulting reaction mixture was stirred for an additional $2 \mathrm{~h}$. When the reaction was finished, as judged by $\mathrm{TLC}\left(\mathrm{SiO}_{2}\right.$, $\mathrm{CH}_{2} \mathrm{Cl}_{2}$ /acetone, 9:1), the solvent was evaporated and the resulting solid residue purified by column chromatography $\left(\mathrm{SiO}_{2}, \mathrm{CH}_{2} \mathrm{Cl}_{2}\right.$ /acetone, 9:1). The compound 9 was isolated as a white solid (85 mg, 71 \%). M.p. $273{ }^{\circ} \mathrm{C} ;{ }^{1} \mathrm{H}$ NMR (400 MHz, $\left.\mathrm{CDCl}_{3}, 25{ }^{\circ} \mathrm{C}\right): \delta=7.43(\mathrm{~s}, 6 \mathrm{H}), 4.41$ (s, $6 \mathrm{H}), 3.78(\mathrm{~s}, 6 \mathrm{H})$, and $2.52 \mathrm{ppm}(\mathrm{s}, 6 \mathrm{H}) ;{ }^{13} \mathrm{C} \mathrm{NMR}\left(100 \mathrm{MHz}, \mathrm{CDCl}_{3}, 25{ }^{\circ} \mathrm{C}\right): \delta=167.7$ (C), $152.6(\mathrm{C}), 137.6(\mathrm{C}), 129.3(\mathrm{C}), 121.2(\mathrm{CH}), 65.0\left(\mathrm{CH}_{2}\right), 51.8\left(\mathrm{CH}_{3}\right), 48.5(\mathrm{CH})$, and 28.3 $\operatorname{ppm}\left(\mathrm{CH}_{2}\right)$; HRMS(ESI): m/z calcd for $\mathrm{C}_{45} \mathrm{H}_{36} \mathrm{O}_{12} \mathrm{Na} 791.2099$ [M+Na] $]^{+}$; found: 791.2098. 


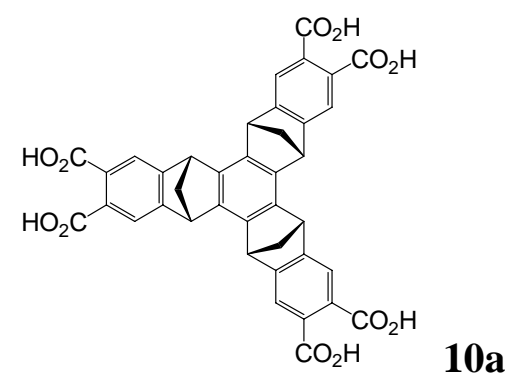

Compound 10a: An aqueous solution of $\mathrm{LiOH} \cdot \mathrm{xH}_{2} \mathrm{O}(60 \mathrm{mg}, 1.43 \mathrm{mmol} ; 2 \mathrm{~mL})$ was added to a solution of 9 (30 mg, $0.04 \mathrm{mmol})$ in THF (2 ml), and subsequently heated at $80{ }^{\circ} \mathrm{C}$ for $2 \mathrm{~h}$. The aqueous phase was acidified with a $10 \%$ aqueous $\mathrm{HCl}$ solution $(1 \mathrm{~mL})$, and the resulting precipitate filtered, washed with water $(2 \mathrm{~mL})$, and dried at $90{ }^{\circ} \mathrm{C}$ under high vacuum. 10a was obtained as a white solid (25.4 mg, 95 \%). M.p. $>300{ }^{\circ} \mathrm{C} ;{ }^{1} \mathrm{H}$ NMR (400 MHz, $\mathrm{CD}_{3} \mathrm{SOCD}_{3}, 25$ $\left.{ }^{\circ} \mathrm{C}\right): \delta=12.67(\mathrm{br}, 6 \mathrm{H}), 7.46(\mathrm{~s}, 6 \mathrm{H}), 4.62(\mathrm{~s}, 6 \mathrm{H})$, and $2.42 \mathrm{ppm}(\mathrm{s}, 6 \mathrm{H}) ;{ }^{13} \mathrm{C} \mathrm{NMR}(100 \mathrm{MHz}$, $\left.\mathrm{CD}_{3} \mathrm{SOCD}_{3}, 25^{\circ} \mathrm{C}\right): \delta=168.8(\mathrm{C}), 153.3(\mathrm{C}), 138.3(\mathrm{C}), 130.6(\mathrm{C}), 121.5(\mathrm{CH}), 65.3\left(\mathrm{CH}_{2}\right)$, and $48.3 \mathrm{ppm}(\mathrm{CH})$; HRMS(ESI): $\mathrm{m} / \mathrm{z}$ calcd for $\mathrm{C}_{39} \mathrm{H}_{24} \mathrm{O}_{12} \mathrm{Na} 707.1150[M+\mathrm{Na}]^{+}$; found: 707.1165 .

Compound 10: A solution of 10a $(15 \mathrm{mg}, 0.03 \mathrm{mmol})$ and $\mathrm{Ac}_{2} \mathrm{O}(2 \mathrm{~mL})$ was heated at $130{ }^{\circ} \mathrm{C}$ for $2 \mathrm{~h}$. The solvent was removed in high vacuo to afford 10 as a white solid (13.0 mg, $90 \%$ ). M.p. $>300{ }^{\circ} \mathrm{C} ;{ }^{1} \mathrm{H}$ NMR (400 MHz, $\left.\mathrm{CD}_{3} \mathrm{SOCD}_{3}, 25{ }^{\circ} \mathrm{C}\right): \delta=7.99$ (s, 6H), $4.77(\mathrm{~s}, 6 \mathrm{H})$, and 2.56 ppm (s, 6H); ${ }^{13} \mathrm{C}$ NMR $\left(100 \mathrm{MHz}, \mathrm{CD}_{3} \mathrm{SOCD}_{3}, 25^{\circ} \mathrm{C}\right): \delta=163.0(\mathrm{C}), 159.8(\mathrm{C}), 138.0(\mathrm{C}), 129.4$ (C), $117.9(\mathrm{CH}), 65.0\left(\mathrm{CH}_{2}\right), 48.3(\mathrm{CH}) ; \mathrm{HRMS}(\mathrm{ESI}): \mathrm{m} / \mathrm{z}$ calcd for $\mathrm{C}_{39} \mathrm{H}_{18} \mathrm{O}_{92} \mathrm{Na} 653.0843$ $[\mathrm{M}+\mathrm{Na}]^{+}$; found: 653.0826 .

Compound 2: A solution of $10(8.0 \mathrm{mg}, 0.013 \mathrm{mmol})$ and benzylamine $(27 \mathrm{mg}, 0.15 \mathrm{mmol})$ in dry toluene $(2 \mathrm{~mL})$ was heated under reflux for $24 \mathrm{~h}$. The solvent was removed in vacuo, and the remaining solid residue was purified by column chromatography $\left(\mathrm{SiO}_{2}\right.$, benzene/acetone, 8:2) to give 2 as a white solid (7.0 mg, $61 \%$ ). M.p. $223{ }^{\circ} \mathrm{C} ;{ }^{1} \mathrm{H}$ NMR $\left(400 \mathrm{MHz}, \mathrm{CDCl}_{3}, 25^{\circ} \mathrm{C}\right): \delta=7.52$ $(\mathrm{s}, 6 \mathrm{H}), 7.36-7.20(\mathrm{~m}, 15 \mathrm{H}), 4.68(\mathrm{~s}, 6 \mathrm{H}), 4.50(\mathrm{~s}, 6 \mathrm{H})$, and $2.58 \mathrm{ppm}(\mathrm{s}, 6 \mathrm{H}) ;{ }^{13} \mathrm{C} \mathrm{NMR}(100$ $\left.\mathrm{MHz}, \mathrm{CDCl}_{3}, 25^{\circ} \mathrm{C}\right): \delta=167.8(\mathrm{C}), 156.6(\mathrm{C}), 137.8(\mathrm{C}), 130.6(\mathrm{C}), 128.5(\mathrm{CH}), 128.4(\mathrm{CH})$, $127.7(\mathrm{C}), 127.5(\mathrm{CH}), 116.1(\mathrm{CH}), 66.0\left(\mathrm{CH}_{2}\right), 49.1(\mathrm{CH})$, and $41.3 \mathrm{ppm}\left(\mathrm{CH}_{2}\right)$; HRMS(ESI): $\mathrm{m} / \mathrm{z}$ calcd for $\mathrm{C}_{60} \mathrm{H}_{39} \mathrm{~N}_{3} \mathrm{O}_{6} \mathrm{Na} 920.2731[M+\mathrm{Na}]^{+}$; found: 920.2722. 


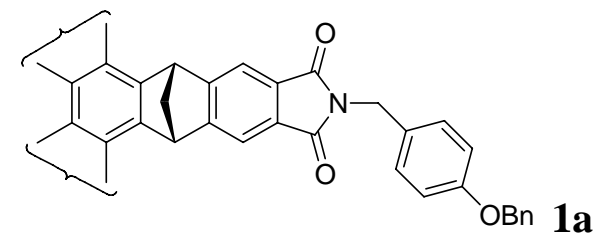

Compound 1a: A solution of $10(26.5 \mathrm{mg}, 0.04 \mathrm{mmol})$ and $14(180 \mathrm{mg}, 0.85 \mathrm{mmol})$ in dry toluene $(5 \mathrm{~mL})$ was heated under reflux for $24 \mathrm{~h}$. Toluene was removed in vacuo, and the solid residue purified by column chromatography $\left(\mathrm{SiO}_{2}\right.$, benzene/acetone, 8:2) to afford $\mathbf{1 a}$ as a white solid (40.2 mg, 79 \%). M.p. $238{ }^{\circ} \mathrm{C} ;{ }^{1} \mathrm{H}$ NMR (400 MHz, $\mathrm{CDCl}_{3}, 25{ }^{\circ} \mathrm{C}$ ): $\delta=7.50$ (s, 6H), 7.347.31 (m, 15H), 7.24 (d, 6H, J=8.8 Hz), 6.82 (d, 6H, J=8.8 Hz), 4.95 (s, 6H), 4.59 (s, 6H), 4.48 (s, $6 \mathrm{H})$, and $2.57 \mathrm{ppm}(\mathrm{s}, 6 \mathrm{H}) ;{ }^{13} \mathrm{C}$ NMR $\left(100 \mathrm{MHz}, \mathrm{CDCl}_{3}, 25^{\circ} \mathrm{C}\right): 167.9(\mathrm{C}), 158.2(\mathrm{C}), 156.5(\mathrm{C})$, $137.8(\mathrm{C}), 136.9(\mathrm{C}), 130.6(\mathrm{C}), 129.9(\mathrm{CH}), 129.1(\mathrm{C}), 128.6(\mathrm{CH}), 127.9(\mathrm{CH}), 127.4(\mathrm{CH})$, $116.1(\mathrm{CH}), 114.8(\mathrm{CH}), 69.9\left(\mathrm{CH}_{2}\right), 65.9\left(\mathrm{CH}_{2}\right), 49.1(\mathrm{CH})$, and $40.8 \mathrm{ppm}\left(\mathrm{CH}_{2}\right)$; HRMS(ESI): $\mathrm{m} / \mathrm{z}$ calcd for $\mathrm{C}_{81} \mathrm{H}_{57} \mathrm{~N}_{3} \mathrm{O}_{9} \mathrm{Na} 1238.3987[\mathrm{M}+\mathrm{Na}]^{+}$; found: 1238.3958 .

Compound 1: A solution of 1a $(6.3 \mathrm{mg}, 0.005 \mathrm{mmol})$ and $10 \% \mathrm{Pd} / \mathrm{C}(5 \mathrm{mg})$ in ethyl acetate (2 $\mathrm{mL}$ ) was stirred under a hydrogen atmosphere and at ambient pressure for $24 \mathrm{~h}$. The catalyst was removed by filtration, the solvent was removed under reduced pressure, and the residue was purified by column chromatography $\left(\mathrm{SiO}_{2}\right.$, benzene/acetone, 7:3) to yield $\mathbf{1}$ as a white solid (4.6 mg, 96 \%). M.p. $220{ }^{\circ} \mathrm{C} \mathrm{dec} ;{ }^{1} \mathrm{H}$ NMR ( $\left.400 \mathrm{MHz}, \mathrm{CDCl}_{3}, 25{ }^{\circ} \mathrm{C}\right): \delta=7.51$ (s, $\left.6 \mathrm{H}\right), 7.04(\mathrm{~d}, 6 \mathrm{H}$, $J=8.5 \mathrm{~Hz}), 6.75$ (s, 3-OH) $6.62(\mathrm{~d}, 6 \mathrm{H}, J=8.5 \mathrm{~Hz}), 4.63(\mathrm{~s}, 6 \mathrm{H}), 4.49$ (s, 6H), $2.58(\mathrm{~s}, 6 \mathrm{H}) ;{ }^{13} \mathrm{C}$ NMR (100 MHz, $\mathrm{CDCl}_{3}, 25^{\circ} \mathrm{C}$ ): 167.8 (C), 156.6 (C), 154.1 (C), 137.7 (C), 130.5 (C), 129.5 $(\mathrm{CH}), 129.0(\mathrm{C}), 128.3(\mathrm{CH}), 116.1(\mathrm{CH}), 115.4(\mathrm{CH}), 66.1\left(\mathrm{CH}_{2}\right), 65.9\left(\mathrm{CH}_{2}\right), 49.1(\mathrm{CH}), 40.4$ $\left(\mathrm{CH}_{2}\right)$; HRMS(ESI): $\mathrm{m} / \mathrm{z}$ calcd for $\mathrm{C}_{60} \mathrm{H}_{39} \mathrm{~N}_{3} \mathrm{O}_{9} \mathrm{Na} 968.2579[\mathrm{M}+\mathrm{Na}]^{+}$; found: 968.2590 .

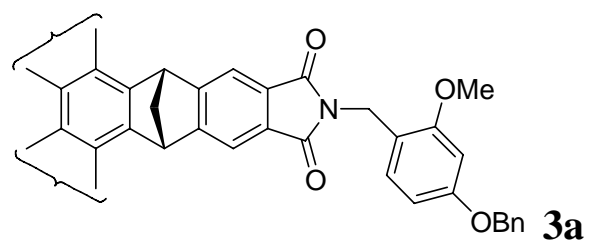

Compound 3a: A solution of $10(10.7 \mathrm{mg}, 0.02 \mathrm{mmol})$ and $18(83.0 \mathrm{mg}, 0.34 \mathrm{mmol})$ in dry toluene $(3 \mathrm{~mL})$ was heated under reflux for $48 \mathrm{~h}$. Toluene was evaporated, and the solid residue was purified by column chromatography $\left(\mathrm{SiO}_{2}\right.$, benzene/acetone, 8:2) to afford $3 \mathbf{a}$ as a white solid (2.4 mg, $11 \%$ ). M.p. $235^{\circ} \mathrm{C} \mathrm{dec} ;{ }^{1} \mathrm{H}$ NMR (400 MHz, $\left.\mathrm{CDCl}_{3}, 25^{\circ} \mathrm{C}\right): \delta=7.54$ (s, $\left.6 \mathrm{H}\right)$, 7.41-7.26 (m, 15H) $7.00(\mathrm{~d}, 6 \mathrm{H}, J=8.4 \mathrm{~Hz}), 6.42(\mathrm{~d}, 6 \mathrm{H}, J=2.0 \mathrm{~Hz}), 6.39\left(\mathrm{dd}, 6 \mathrm{H}, J_{1}=8.4 \mathrm{~Hz}\right.$, 
$J_{2}=2.0 \mathrm{~Hz}$ ), $4.95(\mathrm{~s}, 6 \mathrm{H}), 4.65$ (s, 6H), 4.51 (s, 6H), 3.67 (s, 9H), 2.60 (s, 6H). HRMS(ESI): m/z calcd for $\mathrm{C}_{84} \mathrm{H}_{63} \mathrm{~N}_{3} \mathrm{O}_{12} \mathrm{Na}$ : $1328.4309[M+\mathrm{Na}]^{+}$; found: 1328.4297 .

Compound 3: A solution of 3a (2.4 mg, $0.002 \mathrm{mmol})$ and $10 \% \mathrm{Pd} / \mathrm{C}(2 \mathrm{mg})$ in ethyl acetate $(0.5$ $\mathrm{mL}$ ) was stirred under a hydrogen atmosphere at ambient pressure for $24 \mathrm{~h}$. The catalyst was removed by filtration, the solvent was evaporated in vacuo, and the residue was purified by column chromatography $\left(\mathrm{SiO}_{2}\right.$, benzene/acetone, 7:3) to yield 3 as a white solid (2.0 $\left.\mathrm{mg}, 95 \%\right)$. M.p. $250{ }^{\circ} \mathrm{C} \mathrm{dec} ;{ }^{1} \mathrm{H}$ NMR $\left(400 \mathrm{MHz}, \mathrm{CDCl}_{3}, 25{ }^{\circ} \mathrm{C}\right): \delta=7.52(\mathrm{~s}, 6 \mathrm{H}), 6.86(\mathrm{~d}, 6 \mathrm{H}, J=8.2 \mathrm{~Hz})$, $6.21(\mathrm{~d}, 6 \mathrm{H}, J=2.2 \mathrm{~Hz}), 6.14\left(\mathrm{dd}, 6 \mathrm{H}, J_{1}=8.2 \mathrm{~Hz}, J_{2}=2.2 \mathrm{~Hz}\right), 6.10(\mathrm{~s}, 3 \mathrm{H}), 4.62(\mathrm{~s}, 6 \mathrm{H}), 4.50$ (s, 6H), 3.43 (s, 9H), 2.60 (s, 6H); $\left.{ }^{13} \mathrm{C} \mathrm{NMR} \mathrm{(100} \mathrm{MHz,} \mathrm{CDCl}_{3}, 25^{\circ} \mathrm{C}\right): \delta=167.6(\mathrm{C}), 157.2(\mathrm{C})$, $155.4(\mathrm{C}), 141.2(\mathrm{C}), 137.2(\mathrm{C}), 135.5(\mathrm{CH}), 130.8(\mathrm{C}), 130.3(\mathrm{CH}), 128.6(\mathrm{C}), 115.0(\mathrm{CH}), 97.2$ $(\mathrm{CH}), 66.5\left(\mathrm{CH}_{2}\right), 55.0\left(\mathrm{CH}_{3}\right), 49.1(\mathrm{CH})$, and $42.1 \mathrm{ppm}\left(\mathrm{CH}_{2}\right)$;HRMS(ESI): $\mathrm{m} / \mathrm{z}$ calcd for $\mathrm{C}_{63} \mathrm{H}_{45} \mathrm{~N}_{3} \mathrm{O}_{12} \mathrm{Na} 1058.2895[M+\mathrm{Na}]^{+}$; found: 1058.2924.

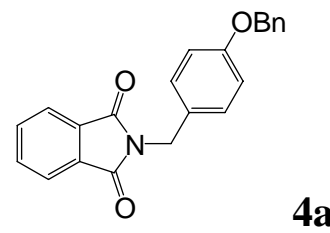

Compound 4a: A mixture of phtalic anhydride (29 mg, $0.12 \mathrm{mmol})$ and $14(50 \mathrm{mg}, 0.23 \mathrm{mmol})$ in toluene $(2 \mathrm{~mL})$ was heated under reflux for $24 \mathrm{~h}$. Toluene was evaporated in vacuo, and the residue was purified by column chromatography $\left(\mathrm{SiO}_{2}\right.$, benzene/acetone, 8:2) to afford $\mathbf{4 a}$ as a white solid (66.5 mg, 99 \%). M.p. $139{ }^{\circ} \mathrm{C} ;{ }^{1} \mathrm{H}$ NMR (400 MHz, $\left.\mathrm{CDCl}_{3}, 25{ }^{\circ} \mathrm{C}\right): \delta=7.83$ (dd, $2 \mathrm{H}$, $\left.J_{1}=3.0 \mathrm{~Hz}, J_{2}=5.5 \mathrm{~Hz}\right), 7.69\left(\mathrm{dd}, 2 \mathrm{H}, J_{1}=3.0 \mathrm{~Hz}, J_{2}=5.5 \mathrm{~Hz}\right), 7.41-7.31(\mathrm{~m}, 7 \mathrm{H}), 6.91(\mathrm{~d}, 2 \mathrm{H}$, $J=8.4 \mathrm{~Hz}), 5.03(\mathrm{~s}, 2 \mathrm{H})$, and $4.78 \mathrm{ppm}(\mathrm{s}, 2 \mathrm{H}) ;{ }^{13} \mathrm{C} \mathrm{NMR}\left(100 \mathrm{MHz}, \mathrm{CDCl}_{3}, 25{ }^{\circ} \mathrm{C}\right): \delta=168.1$ (C), $158.3(\mathrm{C}), 136.9(\mathrm{C}), 133.9(\mathrm{CH}), 132.2(\mathrm{C}), 130.1(\mathrm{CH}), 128.9(\mathrm{C}), 128.6(\mathrm{CH}), 127.9$ $(\mathrm{CH}), 127.4(\mathrm{CH}), 123.3(\mathrm{CH}), 114.9(\mathrm{CH}), 70.0\left(\mathrm{CH}_{2}\right)$, and $41.1 \mathrm{ppm}\left(\mathrm{CH}_{2}\right) ; \mathrm{HRMS}(\mathrm{ESI}): \mathrm{m} / \mathrm{z}$ calcd for $\mathrm{C}_{22} \mathrm{H}_{17} \mathrm{NO}_{3} \mathrm{Na} 366.1106[\mathrm{M}+\mathrm{Na}]^{+}$; found: 366.1083 .

Compound 4: A solution of 4a (65 mg, $0.19 \mathrm{mmol})$ and $10 \% \mathrm{Pd} / \mathrm{C}(10 \mathrm{mg})$ in ethyl acetate (2 $\mathrm{mL}$ ) under an atmosphere of hydrogen was stirred for $24 \mathrm{~h}$. The catalyst was removed by filtration, the solvent was evaporated in vacuo, and the residue was purified by column chromatography $\left(\mathrm{SiO}_{2}\right.$, benzene/acetone, 8:2) to yield 4 as a white solid (46.1 mg, $93 \%$ ). M.p. $201{ }^{\circ} \mathrm{C}$; ${ }^{1} \mathrm{H}$ NMR $\left(400 \mathrm{MHz}, \mathrm{CDCl}_{3}, 25^{\circ} \mathrm{C}\right): \delta=7.83\left(\mathrm{dd}, 2 \mathrm{H}, J_{1}=3.0 \mathrm{~Hz}, J_{2}=5.4 \mathrm{~Hz}\right), 7.70(\mathrm{dd}$, $\left.2 \mathrm{H}, J_{1}=3.0 \mathrm{~Hz}, J_{2}=5.4 \mathrm{~Hz}\right), 7.34(\mathrm{~d}, 2 \mathrm{H}, J=8.5 \mathrm{~Hz}), 6.76(\mathrm{~d}, 2 \mathrm{H}, J=8.5 \mathrm{~Hz}), 4.77(\mathrm{~s}, 2 \mathrm{H})$, 4.72 (s, 3H); ${ }^{13} \mathrm{C}$ NMR (100 MHz, $\left.\mathrm{CDCl}_{3}, 25^{\circ} \mathrm{C}\right): \delta=168.1(\mathrm{C}), 155.2(\mathrm{C}), 133.9(\mathrm{CH}), 132.2$ 
(C), $130.4(\mathrm{CH}), 128.8(\mathrm{C}), 123.3(\mathrm{CH}), 115.4(\mathrm{CH})$, and $41.1 \mathrm{ppm}\left(\mathrm{CH}_{2}\right) ; \mathrm{HRMS}(\mathrm{ESI}): \mathrm{m} / \mathrm{z}$ calcd for $\mathrm{C}_{15} \mathrm{H}_{11} \mathrm{NO}_{3} \mathrm{Na} 276.0637[\mathrm{M}+\mathrm{Na}]^{+}$; found: 276.0619 .

Compound 12: To a solution of 4-hydroxybenzaldehyde 11 (15.0 g, $0.12 \mathrm{~mol}$ ) and $\mathrm{Na}_{2} \mathrm{CO}_{3}$ $(17.0 \mathrm{~g}, 0.16 \mathrm{~mol})$ in anhydrous DMF $(50 \mathrm{~mL})$, benzyl chloride $(17.2 \mathrm{~g}, 0.136 \mathrm{~mol})$ was added under an argon atmosphere. The suspension was stirred vigorously, and heated to $60{ }^{\circ} \mathrm{C}$ for $12 \mathrm{~h}$. On cooling the reaction mixture down to room temperature, the suspension was poured into water $(50 \mathrm{~mL})$ and extracted with diethyl ether $(3 \times 100 \mathrm{~mL})$. The organic phase was washed with brine $(100 \mathrm{~mL})$, dried $\left(\mathrm{MgSO}_{4}\right)$, and concentrated under reduced pressure to give 12 as a white solid (19.3 g, 74 \%). M.p. $69{ }^{\circ} \mathrm{C} ;{ }^{1} \mathrm{H}$ NMR (400 MHz, $\left.\mathrm{CDCl}_{3}, 25{ }^{\circ} \mathrm{C}\right): \delta=9.89$ (s, $1 \mathrm{H}$ ), $7.84(\mathrm{~d}, 2 \mathrm{H}, J=8.8 \mathrm{~Hz}), 7.45-7.33(\mathrm{~m}, 5 \mathrm{H}), 7.08(\mathrm{~d}, 2 \mathrm{H}, J=8.8 \mathrm{~Hz})$, and $5.2 \mathrm{ppm}(\mathrm{s}, 2 \mathrm{H}) ;{ }^{13} \mathrm{C}$ NMR (100 MHz, $\left.\mathrm{CDCl}_{3}, 25^{\circ} \mathrm{C}\right): \delta=190.8$ (CH), 163.7 (C), 135.9 (C), 132.0 (CH), 130.1 (C), $128.7(\mathrm{CH}), 128.3(\mathrm{CH}), 127.5(\mathrm{CH}), 115.1(\mathrm{CH})$, and $70.2 \mathrm{ppm}\left(\mathrm{CH}_{2}\right) ; \mathrm{HRMS}(\mathrm{ESI}): \mathrm{m} / \mathrm{z}$ calcd for $\mathrm{C}_{14} \mathrm{H}_{12} \mathrm{O}_{2} \mathrm{Na} 235.0735[M+\mathrm{Na}]^{+}$; found: 235.0736 .

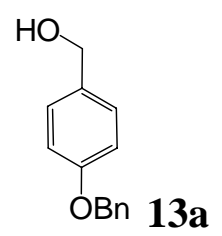

Compound 13a: To a solution of $12(5.0 \mathrm{~g}, 0.03 \mathrm{~mol})$ in THF $(13 \mathrm{~mL})$ and $\mathrm{H}_{2} \mathrm{O}(3 \mathrm{~mL}), \mathrm{NaBH}_{4}$ $(0.57 \mathrm{~g}, 0.02 \mathrm{~mol})$ was added at $0{ }^{\circ} \mathrm{C}$, and the mixture was stirred for 40 minutes. The reaction mixture was quenched with acetone $(2 \mathrm{~mL})$, poured into water $(50 \mathrm{~mL})$, and extracted with EtOAc (3 x $100 \mathrm{~mL})$. The combined organic phase was washed with brine $(100 \mathrm{~mL})$, dried $\left(\mathrm{MgSO}_{4}\right)$, and concentrated under reduced pressure to afford 13a as a white solid (5.5 g, $93 \%$ ). M.p. $87^{\circ} \mathrm{C} ;{ }^{1} \mathrm{H}$ NMR $\left(400 \mathrm{MHz}, \mathrm{CDCl}_{3}, 25^{\circ} \mathrm{C}\right): \delta=7.38-7.26(\mathrm{~m}, 7 \mathrm{H}), 6.98(\mathrm{~d}, 2 \mathrm{H}, J=8.6 \mathrm{~Hz})$, $5.08(\mathrm{~s}, 2 \mathrm{H}), 4.63(\mathrm{~s}, 2 \mathrm{H}) ;{ }^{13} \mathrm{C}$ NMR $\left(100 \mathrm{MHz}, \mathrm{CDCl}_{3}, 25^{\circ} \mathrm{C}\right): \delta=158.4(\mathrm{C}), 137.0(\mathrm{C}), 133.4$ (C), $128.7(\mathrm{CH}), 128.6(\mathrm{CH}), 128.0(\mathrm{CH}), 127.5(\mathrm{CH}), 115.0(\mathrm{CH}), 70.1\left(\mathrm{CH}_{2}\right), 65.1\left(\mathrm{CH}_{2}\right)$; HRMS(ESI): $m / z$ calcd for $\mathrm{C}_{14} \mathrm{H}_{14} \mathrm{O}_{2} \mathrm{Na} 237.0891[M+\mathrm{Na}]^{+}$; found: 237.0890 .

Compound 13: Sodium azide $(1.25 \mathrm{~g}, 0.02 \mathrm{~mol})$ was added to a solution of 13a $(3.4 \mathrm{~g}, 0.02$ $\mathrm{mol})$, and $\mathrm{Ph}_{3} \mathrm{P}(8.8 \mathrm{~g}, 0.03 \mathrm{~mol})$ in $\mathrm{CCl}_{4}(16 \mathrm{~mL})$ and $\mathrm{DMF}(64 \mathrm{~mL})$, and the suspension was heated at $90^{\circ} \mathrm{C}$ for $12 \mathrm{~h}$. The reaction mixture was quenched with water $(20 \mathrm{~mL})$, extracted with diethyl ether $(3 \times 50 \mathrm{~mL})$, and the organic phase dried $\left(\mathrm{MgSO}_{4}\right)$ and concentrated in vacuo. The solid residue was purified by column chromatography $\left(\mathrm{SiO}\right.$, hexanes $\left./ \mathrm{CH}_{2} \mathrm{Cl}_{2}, 7: 3\right)$ to afford 13 
as a white solid (2.8 g, 74 \%). M.p. $35^{\circ} \mathrm{C} ;{ }^{1} \mathrm{H} \mathrm{NMR}\left(400 \mathrm{MHz}, \mathrm{CDCl}_{3}, 25{ }^{\circ} \mathrm{C}\right): \delta=7.47-7.30$ (m, 5H), $7.25(\mathrm{~d}, 2 \mathrm{H}, J=8.8 \mathrm{~Hz}), 6.99(\mathrm{~d}, 2 \mathrm{H}, J=8.8 \mathrm{~Hz}), 5.08(\mathrm{~s}, 2 \mathrm{H}), 4.28(\mathrm{~s}, 2 \mathrm{H}) ;{ }^{13} \mathrm{C}$ NMR $(100$ $\left.\mathrm{MHz}, \mathrm{CDCl}_{3}, 25{ }^{\circ} \mathrm{C}\right): \delta=158.7(\mathrm{C}), 136.6(\mathrm{C}), 130.0(\mathrm{CH}), 128.5(\mathrm{CH}), 128.6(\mathrm{CH}), 128.0$ $(\mathrm{CH}), 127.7(\mathrm{C}), 127.4(\mathrm{CH}), 115.1(\mathrm{CH}), 70.0\left(\mathrm{CH}_{2}\right), 54.3\left(\mathrm{CH}_{2}\right) ; \mathrm{HRMS}(\mathrm{ESI}): \mathrm{m} / \mathrm{z}$ calcd for $\mathrm{C}_{14} \mathrm{H}_{13} \mathrm{~N}_{3} \mathrm{ONa} 262.0956[M+\mathrm{Na}]^{+}$; found: 262.0950 .

Compound 14: A suspension of LAH (0.43 g, $0.01 \mathrm{~mol})$ in anhydrous THF $(50 \mathrm{~mL})$ was slowly added via dropping funnel to a solution of $13(2.7 \mathrm{~g}, 0.01 \mathrm{~mol})$ in $\mathrm{THF}(15 \mathrm{~mL})$ at $0{ }^{\circ} \mathrm{C}$, and the resulting suspension was stirred under an atmosphere of argon for $2 \mathrm{~h}$. The reaction mixture was subsequently quenched with water $(0.5 \mathrm{~mL})$, aqueous $\mathrm{NaOH}(0.5 \mathrm{~mL}, 15 \%)$ and water $(1.5 \mathrm{~mL})$. The obtained slurry was filtered, and the precipitate was washed with diethyl ether $(50 \mathrm{~mL})$. The combined organic phase was dried $\left(\mathrm{MgSO}_{4}\right)$ and concentrated under reduced pressure to afford 14 as a white solid (1.8 g, 75\%). M.p. $117^{\circ} \mathrm{C} ;{ }^{1} \mathrm{H}$ NMR $\left(400 \mathrm{MHz}, \mathrm{CDCl}_{3}, 25^{\circ} \mathrm{C}\right): \delta=7.47-7.26$ $(\mathrm{m}, 5 \mathrm{H}), 7.19(\mathrm{~d}, 2 \mathrm{H}, J=8.8 \mathrm{~Hz}), 6.90(\mathrm{~d}, 2 \mathrm{H}, J=8.8 \mathrm{~Hz}), 5.02(\mathrm{~s}, 2 \mathrm{H}), 3.76(\mathrm{~s}, 2 \mathrm{H})$, and $2.01 \mathrm{ppm}$ (br, 2H); ${ }^{13} \mathrm{C}$ NMR (100 MHz, $\left.\mathrm{CDCl}_{3}, 25^{\circ} \mathrm{C}\right): \delta=157.4$ (C), 136.8 (C), 135.6 (C), $128.2(\mathrm{CH})$, $128.0(\mathrm{CH}), 127.6(\mathrm{CH}), 127.1(\mathrm{CH}), 114.6(\mathrm{CH}), 69.7\left(\mathrm{CH}_{2}\right)$, and $45.5 \mathrm{ppm}\left(\mathrm{CH}_{2}\right)$; HRMS(ESI): $m / z$ calcd for $\mathrm{C}_{14} \mathrm{H}_{15} \mathrm{NONa} 236.1051[M+\mathrm{Na}]^{+}$; found: 235.1054.

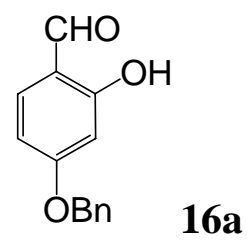

Compound 16a: $\mathrm{NaHCO}_{3}(3.4 \mathrm{~g}, 0.041 \mathrm{~mol})$ and $\mathrm{KI}(0.6 \mathrm{~g}, 0.004 \mathrm{~mol})$ were added to a solution of 2,4-dihydroxybenzaldehyde $15(5.0 \mathrm{~g}, 0.04 \mathrm{~mol})$ in dry acetonitrile $(33 \mathrm{~mL})$ at room temperature and under an argon atmosphere. The mixture was slowly warmed to $60{ }^{\circ} \mathrm{C}$, followed by addition of benzyl chloride (5.96 g, $0.047 \mathrm{~mol})$, upon which the temperature was increased to $90{ }^{\circ} \mathrm{C}$, and the reaction mixture stirred for an additional $16 \mathrm{~h}$. The solvent was removed under reduced pressure, and the resulting solid was partitioned between aqueous $\mathrm{HCl}(0.5 \mathrm{M}, 13 \mathrm{~mL})$ and EtOAc $(25 \mathrm{~mL})$. The aqueous layer was additionally extracted with EtOAc $(2 \times 100 \mathrm{~mL})$, and the combined organic phase was successively washed with aqueous $\mathrm{K}_{2} \mathrm{CO}_{3}(5 \%, 50 \mathrm{~mL})$, water $(50 \mathrm{~mL})$, and brine $(50 \mathrm{~mL})$. The organic phase was dried $\left(\mathrm{MgSO}_{4}\right)$ and concentrated in vacuo to yield the crude product which was subsequently purified by column chromatography $\left(\mathrm{SiO}_{2}\right.$, hexanes/acetone, 8:2) to afford 16a (6.9 g, 83 \%). M.p. $79{ }^{\circ} \mathrm{C} ;{ }^{1} \mathrm{H} \mathrm{NMR}(400 \mathrm{MHz}$, 
$\left.\mathrm{CDCl}_{3}, 25^{\circ} \mathrm{C}\right): \delta=11.47(\mathrm{~s}, 1 \mathrm{H}), 9.72(\mathrm{~s}, 1 \mathrm{H}), 7.44(\mathrm{~d}, 1 \mathrm{H}, J=8.8 \mathrm{~Hz}), 7.42-7.34(\mathrm{~m}, 5 \mathrm{H}), 6.62$ $\left(\mathrm{dd}, 1 \mathrm{H}, J_{1}=2.4 \mathrm{~Hz}, J_{2}=8.8 \mathrm{~Hz}\right), 6.52(\mathrm{~d}, 1 \mathrm{H}, J=2.4 \mathrm{~Hz})$, and $5.12 \mathrm{ppm}(\mathrm{s}, 2 \mathrm{H}) ;{ }^{13} \mathrm{C}$ NMR $(100$ $\left.\mathrm{MHz}, \mathrm{CDCl}_{3}, 25^{\circ} \mathrm{C}\right): \delta=194.4(\mathrm{CH}), 165.9(\mathrm{C}), 164.5(\mathrm{C}), 135.7(\mathrm{C}), 135.3(\mathrm{CH}), 128.8(\mathrm{CH})$, $128.4(\mathrm{CH}), 127.5(\mathrm{CH}), 115.3(\mathrm{C}), 108.9(\mathrm{CH}), 101.7(\mathrm{CH})$, and $70.4 \mathrm{ppm}\left(\mathrm{CH}_{2}\right)$; HRMS(ESI): $\mathrm{m} / \mathrm{z}$ calcd for $\mathrm{C}_{14} \mathrm{H}_{12} \mathrm{O}_{3} \mathrm{Na} 251.0684[\mathrm{M}+\mathrm{Na}]^{+}$; found: 251.0679 .

Compound 16: To a solution of 16a $(1.22 \mathrm{~g}, 5.3 \mathrm{mmol})$ in anhydrous DMF (35 mL), $\mathrm{CH}_{3} \mathrm{I}(0.66$ $\mathrm{mL}, 10.6 \mathrm{mmol})$ and anhydrous $\mathrm{K}_{2} \mathrm{CO}_{3}(0.88 \mathrm{~g}, 6.4 \mathrm{mmol})$ were added. The suspension was stirred at $80^{\circ} \mathrm{C}$ for $4 \mathrm{~h}$. The mixture was cooled to room temperature, poured into water ( $\left.35 \mathrm{~mL}\right)$ and extracted with diethyl ether $(3 \times 100 \mathrm{~mL})$. The organic phase was successively washed with water $(100 \mathrm{~mL})$, aqueous $\mathrm{NaOH}(1 \mathrm{M}, 100 \mathrm{~mL})$, and brine $(100 \mathrm{~mL})$. The solvent was dried $\left(\mathrm{MgSO}_{4}\right)$ and removed under reduced pressure to yield $16\left(1.18\right.$ g, 92\%). M.p. $91{ }^{\circ} \mathrm{C} ;{ }^{1} \mathrm{H} \mathrm{NMR}$ $\left(400 \mathrm{MHz}, \mathrm{CDCl}_{3}, 25^{\circ} \mathrm{C}\right): \delta=10.30(\mathrm{~s}, 1 \mathrm{H}), 7.8(\mathrm{~d}, 1 \mathrm{H}, J=8.6 \mathrm{~Hz}), 7.45-7.34(\mathrm{~m}, 5 \mathrm{H}), 6.63$ $\left(\mathrm{dd}, 1 \mathrm{H}, J_{1}=2.1 \mathrm{~Hz}, J_{2}=8.6 \mathrm{~Hz}\right), 6.54(\mathrm{~d}, 1 \mathrm{H}, J=2.2 \mathrm{~Hz}), 5.13(\mathrm{~s}, 2 \mathrm{H})$, and $3.89 \mathrm{ppm}(\mathrm{s}, 3 \mathrm{H})$. ${ }^{13} \mathrm{C}$ NMR (100 MHz, $\left.\mathrm{CDCl}_{3}, 25{ }^{\circ} \mathrm{C}\right): \delta=188.3(\mathrm{CH}), 165.2(\mathrm{C}), 163.6(\mathrm{C}), 135.9(\mathrm{C}), 130.8$ $(\mathrm{CH}), 128.8(\mathrm{CH}), 128.4(\mathrm{CH}), 126.6(\mathrm{CH}), 119.2(\mathrm{C}), 106.4(\mathrm{CH}), 98.9(\mathrm{CH}), 70.4\left(\mathrm{CH}_{2}\right)$, and $55.6 \mathrm{ppm}\left(\mathrm{CH}_{3}\right)$; HRMS(ESI): $\mathrm{m} / \mathrm{z}$ calcd for $\mathrm{C}_{15} \mathrm{H}_{14} \mathrm{O}_{3} \mathrm{Na} 265.0841[M+\mathrm{Na}]^{+}$; found: 265.0829 .

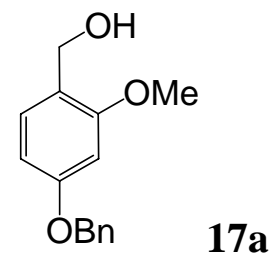

Compound 17a: To a solution of $16(1.1 \mathrm{~g}, 4.6 \mathrm{mmol})$ in THF (4 mL) and water $(1 \mathrm{~mL})$ was added $\mathrm{NaBH}_{4}(100 \mathrm{mg}, 3 \mathrm{mmol})$, and the mixture was stirred at $0{ }^{\circ} \mathrm{C}$ for $2 \mathrm{~h}$. The reaction mixture was quenched with acetone $(0.5 \mathrm{~mL})$, and then poured into water $(10 \mathrm{~mL})$ and extracted with EtOAc $(3 \times 30 \mathrm{~mL})$. The organic phase was washed with brine, dried $\left(\mathrm{MgSO}_{4}\right)$ and concentrated under reduced pressure to afford as $\mathbf{1 7 a}$ as a white solid $\left(1.1 \mathrm{~g}, 99\right.$ \%). M.p. $72{ }^{\circ} \mathrm{C}$; ${ }^{1} \mathrm{H}$ NMR $\left(400 \mathrm{MHz}, \mathrm{CDCl}_{3}, 25^{\circ} \mathrm{C}\right): \delta=7.45-7.32(\mathrm{~m}, 5 \mathrm{H}), 7.17(\mathrm{~d}, 1 \mathrm{H}, J=8.2 \mathrm{~Hz}), 6.57(\mathrm{~d}, 1 \mathrm{H}$, $J=2.2 \mathrm{~Hz}) 6.53\left(\mathrm{dd}, 1 \mathrm{H}, J_{1}=2.2 \mathrm{~Hz}, J_{2}=8.2 \mathrm{~Hz}\right), 5.07(\mathrm{~s}, 2 \mathrm{H}), 4.62(\mathrm{~s}, 2 \mathrm{H})$, and $3.83 \mathrm{ppm}(\mathrm{s}$, $3 \mathrm{H}) ;{ }^{13} \mathrm{C} \mathrm{NMR}\left(100 \mathrm{MHz}, \mathrm{CDCl}_{3}, 25^{\circ} \mathrm{C}\right): \delta=159.8(\mathrm{C}), 158.6(\mathrm{C}), 136.8(\mathrm{C}), 129.6(\mathrm{CH}), 128.5$ $(\mathrm{CH}), 128.0(\mathrm{CH}), 127.5(\mathrm{CH}), 122.0(\mathrm{C}), 104.8(\mathrm{CH}), 99.4(\mathrm{CH}), 70.1\left(\mathrm{CH}_{2}\right), 61.6\left(\mathrm{CH}_{2}\right)$, and 55.3 ppm $\left(\mathrm{CH}_{3}\right)$; HRMS(ESI): $\mathrm{m} / \mathrm{z}$ calcd for $\mathrm{C}_{15} \mathrm{H}_{16} \mathrm{O}_{3} \mathrm{Na} 267.0992[\mathrm{M}+\mathrm{Na}]^{+}$; found: 267.0998 . 
Compound 17: A mixture of 17a (500 mg, $2.1 \mathrm{mmol})$, sodium azide (162 mg, $2.5 \mathrm{mmol})$, and $\mathrm{Ph}_{3} \mathrm{P}(1.3 \mathrm{~g}, 4.3 \mathrm{mmol})$ in $\mathrm{CCl}_{4}(2 \mathrm{~mL})$ and DMF $(8 \mathrm{~mL})$ was heated at $90{ }^{\circ} \mathrm{C}$ for $48 \mathrm{~h}$. The reaction mixture was washed with water $(10 \mathrm{~mL})$, extracted with diethyl ether $(3 \times 50 \mathrm{~mL})$, and the organic layer dried $\left(\mathrm{MgSO}_{4}\right)$ and concentrated under reduced pressure. The crude product was purified by column chromatography $\left(\mathrm{SiO}_{2}\right.$, benzene/acetone, 9:1) to yield $\mathbf{1 7}$ as a viscous oil (340 mg, 62 \%). M.p. ${ }^{1} \mathrm{H}$ NMR (400 MHz, $\left.\mathrm{CDCl}_{3}, 25^{\circ} \mathrm{C}\right): \delta=7.46-7.33(\mathrm{~m}, 5 \mathrm{H}), 7.15(\mathrm{~d}, 1 \mathrm{H}$, $J=8.2 \mathrm{~Hz}), 6.58(\mathrm{~d}, 1 \mathrm{H}, J=2.2 \mathrm{~Hz}), 6.55\left(\mathrm{dd}, 1 \mathrm{H}, J_{1}=2.2 \mathrm{~Hz}, J_{2}=8.2 \mathrm{~Hz}\right), 5.07(\mathrm{~s}, 2 \mathrm{H}), 4.29$ (s, 2H), and $3.83 \mathrm{ppm}(\mathrm{s}, 3 \mathrm{H}) ;{ }^{13} \mathrm{C}$ NMR (100 MHz, $\left.\mathrm{CDCl}_{3}, 25^{\circ} \mathrm{C}\right): \delta=160.5$ (C), 158.9 (C), 136.8 (C), $131.0(\mathrm{CH}), 128.7(\mathrm{CH}), 128.1(\mathrm{CH}), 127.6(\mathrm{CH}), 116.0(\mathrm{C}), 105.0(\mathrm{CH}), 99.5(\mathrm{CH}), 70.2$ $\left(\mathrm{CH}_{2}\right), 55.4\left(\mathrm{CH}_{3}\right)$, and $49.9 \mathrm{ppm}\left(\mathrm{CH}_{2}\right)$; HRMS(ESI): $\mathrm{m} / \mathrm{z}$ calcd for $\mathrm{C}_{15} \mathrm{H}_{15} \mathrm{NO}_{2} 241.1103$ [M$\left.\mathrm{N}_{2}\right]^{+}$; found: 241.0946.

Compound 18: A solution of 17 (330 mg, $1.26 \mathrm{mmol})$ in dry THF (3 mL) was added dropwise, via syringe, into the suspension of LAH $(50 \mathrm{mg}, 1.26 \mathrm{mmol})$ in THF $(10 \mathrm{~mL})$ at $0{ }^{\circ} \mathrm{C}$ and under an argon atmosphere. After $2 \mathrm{~h}$, the reaction mixture was successively quenched with water $(0.1$ $\mathrm{mL})$, aqueous $\mathrm{NaOH}(15 \%, 0.1 \mathrm{~mL})$ and water $(0.3 \mathrm{~mL})$. The obtained suspension was filtered and the collected precipitate washed with diethyl ether $(20 \mathrm{~mL})$. The combined organic phase was dried $\left(\mathrm{MgSO}_{4}\right)$ and concentrated in vacuo to afford 18 as a viscous oil (245 $\left.\mathrm{mg}, 82 \%\right)$, without further purification. ${ }^{1} \mathrm{H}$ NMR $\left(400 \mathrm{MHz}, \mathrm{CDCl}_{3}, 25^{\circ} \mathrm{C}\right): \delta=7.43-7.31(\mathrm{~m}, 5 \mathrm{H}), 7.10(\mathrm{~d}$, $1 \mathrm{H}, J=8.1 \mathrm{~Hz}), 6.55(\mathrm{~d}, 1 \mathrm{H}, J=2.1 \mathrm{~Hz}), 6.51\left(\mathrm{dd}, 1 \mathrm{H}, J_{1}=2.1 \mathrm{~Hz}, J_{2}=8.1 \mathrm{~Hz}\right), 5.08(\mathrm{~s}, 2 \mathrm{H})$, 3.83 (s, 3H), 3.76 (s, 2H), 1.59 (br, 2H); ${ }^{13} \mathrm{C}$ NMR (100 MHz, $\left.\mathrm{CDCl}_{3}, 25{ }^{\circ} \mathrm{C}\right): \delta=159.1(\mathrm{C})$, $158.4(\mathrm{C}), 136.9(\mathrm{C}), 128.9(\mathrm{CH}), 128.5(\mathrm{CH}), 127.9(\mathrm{CH}), 127.5(\mathrm{CH}), 124.8(\mathrm{C}), 104.6(\mathrm{CH})$, $99.4(\mathrm{CH}), 70.1\left(\mathrm{CH}_{2}\right), 55.3\left(\mathrm{CH}_{3}\right)$, and $42.1 \mathrm{ppm}\left(\mathrm{CH}_{2}\right)$; HRMS(ESI): $\mathrm{m} / \mathrm{z}$ calcd for $\mathrm{C}_{15} \mathrm{H}_{17} \mathrm{NO}_{2} \mathrm{Na} 266.1157[\mathrm{M}+\mathrm{Na}]^{+}$; found: 266.1153 .

\section{References:}

(1) For a detailed procedure see: LaPlanche, L. A., Thompson, H. B.; Rogers, M. T. J. Phys. Chem. 1965, 69, 1482.

(2) Frisch, M. J.; Trucks, G. W.; Schlegel, H. B.; Scuseria, G. E.; Robb, M. A.; Cheeseman, J. R.; Montgomery, J. A., Jr.; Vreven, T.; Kudin, K. N.; Burant, J. C.; Millam, J. M.; Iyengar, S. S.; Tomasi, J.; Barone, V.; Mennucci, B.; Cossi, M.; Scalmani, G.; Rega, N.; 
Pettersson, G. A.; Nakatsuji, H; Hada, M.; Ehara, M.; Toyota, K.; Fukuda, R.; Hasegawa, J.; Ishida, M.; Nakajima, T.; Honda, Y.; Kitao, O.; Nakai, H.; Klene, M.; Li, X.; Knox, J. E.; Hratchian, H. P.; Cross, J. B.; Adamo, C.; Jaramillo, J.; Gomperts, R.; Stratmann, R. E.; Yazyev, O.; Austin, A. J.; Cammi, R.; Pomelli, C.; Ochterski, J. W.; Ayala, P. Y.; Morokuma, K.; Voth, G. A.; Salvador, P.; Dannenberg, J. J.; Zakrzewski, V. G.; Dapprich, S.; Daniels, A. D.; Strain, M. C.; Farkas, O.; Malick, D. K.; Rabuck, A. D.; Raghavachari, K.; Foresman, J. B.; Ortiz, J. V.; Cui, Q.; Baboul, A. G.; Clifford, S.; Cioslowski, J.; Stefanov, B. B.; Lui, G.; Liashenko, A.; Piskorz, P.; Komaromi, I.; Martin, R. L.; Fox, D. J.; Keith, T.; Al-Laham, M. A.; Peng, C. Y.; Nanayakkara, A.; Challacombe, M.; Gill, P. M. W.; Johnson, B.; Chen, W.; Wong, M. W.; Gonzalez, C.; Pople, J. A. Gaussian 03, Revision C.02, Gaussian, Inc.; Wallingford, CT, 2004. 